\title{
Can broad-spectrum multinutrients treat symptoms of antenatal depression and anxiety and improve infant development? Study protocol of a double blind, randomized, controlled trial (the 'NUTRIMUM' trial)
}

Hayley A. Bradley ${ }^{1 *}$, Siobhan A. Campbell1, Roger T. Mulder², Jaqueline M. T. Henderson', Lesley Dixon³, Joseph M. Boden ${ }^{2}$ and Julia J. Rucklidge ${ }^{1}$

\begin{abstract}
Background: Untreated antenatal depression and anxiety can be associated with short and long term health impacts on the pregnant woman, her infant and the rest of the family. Alternative interventions to those currently available are needed. This clinical trial aims to investigate the efficacy and safety of a broad-spectrum multinutrient formula as a treatment for symptoms of depression and anxiety in pregnant women and to determine the impact supplementation has on the general health and development of the infant.

Methods: This randomised, controlled trial will be conducted in Canterbury, New Zealand between April 2017 and June 2022. One hundred and twenty women aged over 16 years, between 12 and 24 weeks gestation and who score $\geq 13$ on the Edinburgh Postnatal Depression Scale (EPDS) will be randomly assigned to take the intervention $(n=60)$ or an active control formula containing iodine and riboflavin $(n=60)$ for 12 weeks. After 12 weeks, participants can enter an open-label phase until the birth of their infant and naturalistically followed for the first 12 months postpartum. Infants will be followed until 12 months of age. Randomisation will be computer-generated, with allocation concealment by opaque sequentially numbered envelopes. Participants and the research team including data analysts will be blinded to group assignment. The EPDS and the Clinical Global Impressions Scale of Improvement (CGI-I) will be the maternal primary outcome measures of this study and will assess the incidence of depression and anxiety and the improvement of symptomatology respectively. Generalized linear mixed effects regression models will analyse statistical differences between the multinutrient and active control group on an intent-to-treat basis. A minimum of a three-point difference in EPDS scores between the groups will identify clinical significance. Pregnancy outcomes, adverse events and side effects will also be monitored and reported.
\end{abstract}

(Continued on next page)

\footnotetext{
*Correspondence: hayley.bradley@pg.canterbury.ac.nz

'School of Psychology, Speech and Hearing, University of Canterbury, Private Bag 4800, Christchurch 8041, New Zealand

Full list of author information is available at the end of the article
}

(c) The Author(s). 2020 Open Access This article is licensed under a Creative Commons Attribution 4.0 International License, which permits use, sharing, adaptation, distribution and reproduction in any medium or format, as long as you give appropriate credit to the original author(s) and the source, provide a link to the Creative Commons licence, and indicate if changes were made. The images or other third party material in this article are included in the article's Creative Commons licence, unless indicated otherwise in a credit line to the material. If material is not included in the article's Creative Commons licence and your intended use is not permitted by statutory regulation or exceeds the permitted use, you will need to obtain permission directly from the copyright holder. To view a copy of this licence, visit http://creativecommons.org/licenses/by/4.0/ The Creative Commons Public Domain Dedication waiver (http://creativecommons.org/publicdomain/zero/1.0/) applies to the data made available in this article, unless otherwise stated in a credit line to the data. 
(Continued from previous page)

Discussion: Should the multinutrient formula be shown to be beneficial for both the mother and the infant, then an alternative treatment option that may also improve the biopsychosocial development of their infants can be provided for pregnant women experiencing symptoms of depression and anxiety.

Trial registration: Trial ID: ACTRN12617000354381; prospectively registered at Australian New Zealand Clinical Trials Registry on 08/03/2017.

Keywords: Antenatal, Perinatal, Pregnancy, Depression, Anxiety, Treatment, Intervention, Micronutrients, Infant development

\section{Background}

Depression and anxiety are the most common mental health problems during pregnancy and are amongst the leading causes of maternal morbidity and mortality worldwide [1]. Internationally, rates of antenatal depression and anxiety range between $3.5-18.4 \%[2,3]$ and $6.6-24.7 \%[3$, 4] respectively. In New Zealand, rates of antenatal depression and anxiety appear to be higher than this with between 12 and $22 \%$ of pregnant women experiencing depression [5, 6] and 20-25\% suffering from anxiety [5]. Antenatal depression and anxiety are highly comorbid and begin in or continue into pregnancy. The signs and symptoms are typically the same as those for depression and anxiety in the non-pregnant population [7].

Antenatal depression and anxiety is associated with short and long-term health consequences for not only the pregnant women affected but the infant and rest of the family. Pregnancy and neonatal complications such as hypertension, preeclampsia, and gestational diabetes [8]; low birth weight, foetal growth restriction $[9,10]$ and preterm birth [11-13] are more likely in individuals who experience antenatal depression and anxiety. Depression and anxiety during pregnancy have also been associated with poor cognitive, emotional and behavioural development of the infant [12, 14-16], poor maternal attachment to the infant and increased risk of depression in partners $[15,16]$.

The Royal Australian and New Zealand College of Psychiatrists recommend the use of pharmacological interventions such as antidepressants as the first line of treatment to address severe depression and anxiety during pregnancy, despite the lack of evidence supporting the efficacy of its use [17] and the reluctance of women to use this form of treatment during pregnancy [18-20].

Over the last few years, retrospective observational studies have been increasingly recognizing the risks associated with in-utero exposure to antidepressants including congenital malformations [21, 22], poor neonatal adaptation syndrome $[23,24]$ and persistent pulmonary hypertension in the infant $[25,26]$. Offspring exposed to antidepressant medication during pregnancy are also at greater risk of neurodevelopmental delay [27-31], impairments to language skills [32] and of developing depression during adolescence [33]. Although recent studies have concluded that foetal exposure to antidepressant medication poses no risk to developing an autism spectrum disorder (ASD) or attention-deficit/ hyperactivity disorder (ADHD) [33-35], most found that the incidence of these disorders were two fold prior to controlling for confounding variables. For all pregnant women suffering from depression and/or anxiety, the risks of exposing the foetus to antidepressant medication during pregnancy must be weighed against the risks to both the mother and the foetus of untreated depression and/or anxiety during the antenatal period [36].

The first line of treatment recommended for mild to moderate depression and anxiety during pregnancy is psychological interventions such as cognitive-behavioural therapy and interpersonal therapy (IPT) [17]. Although evidence from open trials and RCTs to support the efficacy of IPT for depression $[37,38]$ and open trials of CBT and mindfulness for anxiety [39]are increasing and the majority of pregnant women prefer this form of treatment over medication, many have difficulty accessing these treatments due to issues with time, stigma, cost and childcare [40].

It is evident that current treatments for depression and anxiety during the antenatal period may not be either accessible or acceptable to many women struggling with these symptoms during pregnancy. Alternative interventions that are safe, acceptable and more accessible therefore need to be identified.

Nutritional interventions present a possible treatment option for psychological symptoms presenting during pregnancy. Indeed, evidence is emerging from cohort and cross-sectional studies suggesting that diet plays a significant role in maternal mental health during the antenatal period where poor diet quality has been associated with symptoms of antenatal depression, anxiety and stress [41] and a healthy dietary pattern has been associated with lower symptoms [42] and an inverse association with antenatal and postnatal anxiety and prenatal depression [43]. Furthermore, a recent systematic review of cross sectional and cohort studies found that a traditional Japanese and UK diet during pregnancy was associated with a lower risk of prenatal depression and anxiety respectively [43]. The review found no significant 
association between a Western dietary pattern and symptoms of perinatal depression and anxiety.

It is well known that a poor diet can lead to nutritional deficiencies and indeed, pregnancy and lactation is a period where nutritional deficiencies are more likely to arise given the increased demands on the pregnant woman's body. The pregnant woman therefore is at a greater risk of developing nutritional deficiencies. Some studies investigating the association between blood concentration of various nutrients and mental health have linked lower serum levels of nutrients such as vitamin D, zinc, folate and vitamin B12 with increased depressive symptoms [44-47] as well as selenium, fats and fatty acids, whereas other have found no association $[48,49]$. There is currently insufficient evidence on deficiencies to predict who is at risk of developing antenatal depression and anxiety and as such, more research is needed.

While it is important to investigate the impact of nutrients individually, it is rare for nutritional deficiencies to occur in isolation and instead, given that they are not consumed singularly in the diet, deficiencies in multiple micronutrients are more likely [50]. Nutrients are required for the synthesis of neurotransmitters and interact synergistically and antagonistically with each other for proper functioning of the mind and body, as such, a combined approach is likely more appropriate [51]. Indeed, evidence has accumulated over the last 10 years showing that broad spectrum multinutrient interventions may provide larger effects for a variety of psychological conditions including depression, anxiety, and ADHD relative to any single nutrient alone [52].

While a number of studies have focused on the prevention of postnatal depression using micronutrient supplementation, investigations for efficacious treatments of antenatal depression and anxiety has been relatively neglected until recently. Only two studies have been conducted to date that assist with determining whether nutrients can alter the course of depression during pregnancy in women who are symptomatic. A randomised controlled trial examined the effects of omega 3 fatty acids compared with a placebo in women diagnosed with a major depressive disorder during pregnancyand found that the omega 3 fatty acids had a greater effect on reducing depression scores relative to placebo [53]. A second randomized controlled trial conducted in Vietnam found that women scoring in the highest tertile for depressive symptoms (as measured by the CES-D) at preconception, had lower depression scores during the first and second trimesters of pregnancy after taking multiple micronutrients or a combined iron-folic acid formula during the preconception period than women who consumed a folic acid only formula [54].

To date, no studies have been conducted examining the efficacy of nutritional supplements for the treatment of antenatal anxiety in women who are symptomatic. More specifically, no study has yet addressed whether broad-spectrum multinutrients (vitamins and minerals taken in combination) is an efficacious treatment for women who experience symptoms of depression and anxiety during pregnancy. This study therefore aims to investigate the efficacy and safety of nutrients in a pregnant population experiencing such symptoms. This study also aims to offer some etiological and mechanistic insight into the relationship between multinutrients and mood by examining levels of certain nutrients and biomarkers of inflammation such as homocysteine and cytokines as predictors and mediators of treatment response. Indeed, concentrations of various proinflammatory cytokines have been found to be higher in the depressed adult population [55] and emerging evidence is finding a link between antenatal depression and elevated levels of inflammation; however, the findings are mixed [56]. Nevertheless, studies in support of the inflammatory theory have found a relationship between antenatal depression and an increased risk of various foetal and maternal morbidities such as preeclampsia, preterm birth, gestational diabetes which are known to be associated with increased inflammation [56].

Given that nutrients serve an important role in the structural and functional development of the foetus [57], this study will also examine the impact multinutrient exposure in utero has on infant development. Indeed, deficiencies in certain nutrients and/or an unhealthy diet during pregnancy have been associated with congenital malformations, poor pregnancy, labour and birth outcomes and impaired cognitive [58], long-term emotional behavioural development [59] and hyperactivity-inattention symptoms [59]. While there is limited evidence for the association between maternal diet and beneficial outcomes for offspring, the observational study, KOMCHS in Japan showed that behavioural problems in childhood were less likely in children whose mothers consumed a diet high in vegetables, fruit and vitamin $\mathrm{C}$ during pregnancy [60] and used supplements of folate, vitamin B2 and vitamin B6 [61]. A Danish cohort study (DNBC) reported the risk for hyperkinetic disorders and treatment for ADHD to be lower in children whose mothers used multivitamins early in pregnancy compared to those who consumed folic acid only [62]. There have been limited studies to date examining the impact of diet and dietary supplementation on infants whose mothers experienced mental health difficulties during the antenatal period.

Supplementation of certain nutrients such as folic acid, vitamin $\mathrm{A}$ and vitamin $\mathrm{D}$ at specific time points during the antenatal period has been associated with improved physical health and emotional development outcomes in childhood and reduced likelihood of later mental illnesses $[63,64]$. For supplementation of a broadspectrum multinutrients, evidence from the developing 
world has shown a reduced risk of low birth weight and found no significant adverse effects overall in infants exposed to multinutrients in utero $[65,66]$. A birth cohort study conducted in China found that prenatal multinutrient supplementation compared to iodine-folic acid supplementation was associated with increased scores of communication, gross motor, fine motor, problemsolving and personal-social skills in offspring at 36 months old [67]. In a follow up study of an RCT in Nepal where access to food is limited, infants exposed to a multi-vitamin and mineral supplement in utero were found to have a higher birth weight and increased body weight/size at 2 years of age than infants exposed to an iron and folic acid supplement [68]. The effects of multinutrient supplementation on these outcomes is unknown in infants whose mothers experienced mental health difficulties during the antenatal period.

It seems plausible that supplementation with a broad range of nutrients during pregnancy may also be of benefit to the foetus and infant by improving foetal growth and biopsychosocial outcomes. This study therefore additionally aims to explore and begin to document the health and developmental outcomes of infants exposed to multinutrients in-utero.

\section{Aims}

This trial aims to investigate the efficacy and safety of a broad-spectrum multinutrient formula compared to an active control formula for the treatment of symptoms of antenatal depression and anxiety using a double blind randomized controlled design. We anticipate that women randomized to receive the multinutrient formula will show a greater improvement in depressive and anxiety symptoms compared to women taking the active control formula. We hypothesise that improvements will generalise to secondary measures of sleep, stress, emotion regulation and quality of life.

An exploratory aspect of this trial aims to document potential effects of an enriched nutrient environment during utero on infant outcomes. As such, we will explore whether length of exposure to nutrients is a predictor of infant temperamental outcomes. We hypothesise that a more nutrient-rich foetal environment will contribute to more positive long-term health and developmental outcomes for the infant.

\section{Methods/design} Trial design

This randomized, double-blind, controlled trial is designed to compare the efficacy and safety of a broadspectrum multinutrient formula to an active control formula for the treatment of depressive and anxiety symptoms in pregnant women, allocated in a 1:1 ratio. The 12 week RCT phase of the trial will be followed by an open label phase where participants can take the multinutrient intervention until the birth of their infant. The open label phase was included in order to provide participants with the opportunity to try the nutrients regardless of the random allocation in the RCT phase without breaking the blind. Participants will be followed up naturalistically until 12 months postpartum.

\section{Study setting}

The trial will be conducted at the University of Canterbury, Christchurch, New Zealand. Enrolment of the first participant occurred on 12 April 2017; the last participant is anticipated to enrol by December 2020.

\section{Eligibility criteria}

Pregnant women who are between 12 and 24 weeks gestation will be recruited and followed throughout their pregnancy until 12 months postpartum. The inclusion criteria are aged $\geq 16$ years; low risk singleton pregnancy; free from psychiatric medication for 4 weeks; score of $\geq 13$ on the Edinburgh Postnatal Depression Scale (EPDS) during their second trimester and deemed reliable and compliant with the protocol. The exclusion criteria include regular vomiting; current/recent significant pregnancy complications (e.g. placenta praevia, preeclampsia, gestational diabetes), known foetal abnormalities; serious current or historical medical condition (e.g. hypertension, kidney disease); known allergy to the ingredients of the intervention; known metabolic condition (e.g. Wilson's disease, hemochromatosis); untreated or unstable thyroid disease; known neurological disorder (e.g. epilepsy, multiple sclerosis, narcolepsy); desire to continue taking prenatal supplements that either exceed the upper limit or are not required for medical purposes (decisions discussed and made on a case-by-case basis).

All participants will be invited to enrol their infant in the study examining infant development over the first 12 months of life.

\section{Intervention}

Participants will be randomly assigned to receive either a multinutrient formula (Daily Essential Nutrients (DEN)) or an active control formula containing iodine and riboflavin for a 12-week period in order to allow enough time for the treatment to reach a substantial effect. Iodine is recommended to be taken throughout the duration of pregnancy in New Zealand and will therefore be used as an active control so that an additional iodine supplement will not need to be taken alongside the study interventions.

The full dose of 12 capsules will be taken as four capsules three times daily. Titration to the full dose will occur over a 7-day period whereby participants take one capsule, three times each day with the dose increasing by three capsules every second day until the maximum dose is 
achieved. Taken at the full dose, both formulas provide the daily supplemental intake of iodine for pregnant and lactating women as recommended by the New Zealand Ministry of Health. The dose of iodine in the active control formula will be distributed across 12 capsules such that participants randomized to the active control condition consume the same number of capsules. The multinutrient formula contains riboflavin (vitamin $\mathrm{B}_{2}$ ), a vitamin known to colour the urine. Riboflavin will be added to the active control formula to mimic the possible effect on urine colour in order to maintain the double-blind.

Both the multinutrient and the active control formulas are similar in appearance and will be taken orally in capsule form. They will be packaged in white opaque bottles containing two vanilla sachets to ensure all the capsules smell the same. Each bottle will have a label identifying the participant number. Both formulas are suitable for participants with intolerances or allergies to gluten, dairy and soy. The full list of ingredients and doses can be viewed in Table 1.

DEN was chosen for this study as the combination of nutrients it contains is the most studied combination in the world for the treatment of psychiatric illnesses [51] and has found robust effects on a range of psychological symptoms that are also implicated in antenatal depression and anxiety [52, 69-72]. Furthermore, the safety and tolerability of this combination of multinutrients is well documented in both adults and children [72, 73].

During the RCT phase of the trial, participants will be able to continue taking omega 3 and probiotic supplements if they were taking these prior to screening for the trial. Participants will also be able take iron, if needed, at any time during the pregnancy and will be able to continue any form of psychotherapy that had begun prior to screening. Participants will be withdrawn from the study if they are prescribed and take any psychiatric medication given the potential interaction with nutrients. Participants will be encouraged before enrolment in the trial to avoid taking additional nutrients, other than those needed for medical reasons, throughout the duration of the trial in order to minimize the risk of adverse events. However, they may be withdrawn from the trial if the dose of a prescribed vitamin or mineral supplement exceeds the upper limit. Decisions on continued participation in the trial will be made on a caseby-case basis. The upper limit is the maximum dose of a nutrient that can be taken without any adverse effects.

Following the 12-week RCT period, all participants will be invited to enter an open label phase until the birth of their infants and where the capsule dose will be identical and follow the same titration procedure as the RCT phase. The product is commercially available for participants to purchase should they wish to continue taking the multinutrients post-trial.
Table 1 Intervention ingredients

\begin{tabular}{ll}
\hline Daily Essential Nutrients Supplement Facts & \\
Amount per serving (12 capsules) & \\
Vitamin A (as retinyl palmitate) & $5760 \mathrm{IU}$ \\
Vitamin C (as ascorbic acid) & $600 \mathrm{mg}$ \\
Vitamin D (as cholecalciferol) & $3000 \mathrm{IU}$ \\
Vitamin E (as d-alpha tocopheryl succinate) & $360 \mathrm{IU}$ \\
Vitamin K (75\% as phylloquinone; 25\% as menaquinone-7) & $120 \mathrm{mcg}$ \\
Thiamin (as thiamin mononitrate) & $60 \mathrm{mg}$ \\
Riboflavin & $18 \mathrm{mg}$ \\
Niacin (as niacinamide) & $90 \mathrm{mg}$ \\
Vitamin B6 (as pyridoxine hydrochloride) & $69.9 \mathrm{mg}$ \\
Folate (as L-methylfolate calcium) & $801 \mathrm{mcg}$ \\
Vitamin B12 (as methylcobalamin) & $900 \mathrm{mcg}$ \\
Biotin & $1080 \mathrm{mcg}$ \\
Pantothenic acid (as d-calcium pantothenate) & $30 \mathrm{mg}$ \\
Calcium (as chelate) & $1320 \mathrm{mg}$ \\
Iron (as chelate) & $13.8 \mathrm{mg}$ \\
Phosphorus (as chelate) & $840 \mathrm{mg}$ \\
lodine (as chelate) & $204 \mathrm{mcg}$ \\
Magnesium (as chelate) & $600 \mathrm{mg}$ \\
Zinc (as chelate) & $48 \mathrm{mg}$ \\
Selenium (as chelate) & $204 \mathrm{mcg}$ \\
Copper (as chelate) & $7.2 \mathrm{mg}$ \\
Manganese (as chelate) & $9.6 \mathrm{mg}$ \\
Chromium (as chelate) & $624 \mathrm{mcg}$ \\
Molybdenum (as chelate) & $144 \mathrm{mcg}$ \\
Potassium (as chelate) & $240 \mathrm{mg}$
\end{tabular}

Proprietary blend: Choline bitartrate, Alpha-lipoic acid, Mineral wax, Inositol, Acetyl-L-carnitine, Grape seed extract, Ginkgo biloba leaf extract, Lmethionine, N-acetyl-L-cysteine, Boron (as chelate), Vanadium (as chelate), Lithium orotate (as chelate), Nickel (as chelate)

Other ingredients: Vegetarian capsule (hypromellose), Microcrystalline cellulose, Magnesium stearate, Silicon dioxide, Titanium dioxide

\section{Active Control Supplement Facts}

Amount per serving (12 capsules)

$\begin{array}{ll}\text { Riboflavin } & 1.2 \mathrm{mg} \\ \text { Potassium lodide } & 150 \mathrm{mcg} \\ \text { Silicon dioxide } & 30 \mathrm{mg} \\ \text { Magnesium stearate } & 60 \mathrm{mg} \\ \text { Microcrystalline cellulose } & 6 \mathrm{~g}\end{array}$

\section{Outcomes}

Figure 1 displays the outcome measures of the study and the time points at which each measure will be administered. Demographic characteristics including age, ethnicity, education, occupation, household income, number in household, children and marital status will be collected in a screening assessment. All self-report measures will be 


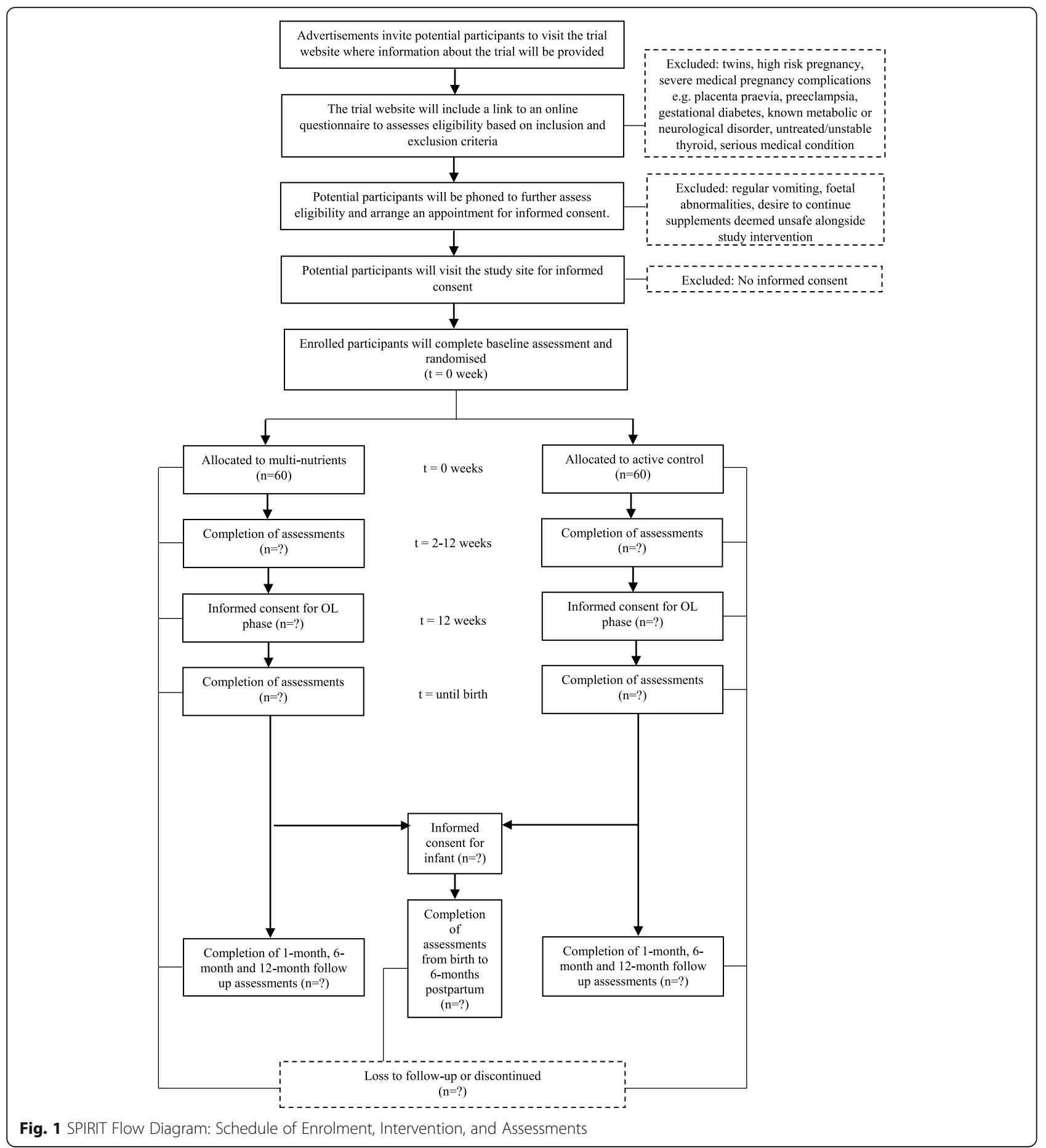

independently completed by participants via the web-based data collection system, Qualtrics.

\section{Maternal primary outcome measures}

The Edinburgh Postnatal Depression Scale (EPDS) [74] is a 10 item self-report questionnaire designed to assess the cognitive and affective symptoms of depression and anxiety over the previous 7 days. The EPDS is the most widely used screening questionnaire for postpartum depression [75] in both research and clinical practice and has also been validated as a screening measure for probable depression during pregnancy [76-78]. Each item on the EPDS is rated on a four-point scale, with a total score ranging from 0 to 30, with higher scores indicating greater levels of distress. A cut off score of 13 has been found to have the optimum specificity and 
sensitivity in detecting an incidence of major depression in the postnatal period [74]; however, cut off scores during the antenatal period are controversial and culturally dependent; ranging from 4.5 to 13.5 [79]. Despite disagreements in the cut off score for the incidence of major depression during the antenatal period, a cut off score of $\geq 13$ will be used in this study to identify the incidence of perinatal depression. A cut-off score of $\geq 13$ has been used in prevalence studies in New Zealand [5, 6] and has been shown to not miss any women in need of help for their mood in Australian clinical practice [80]. A cut off score of 10 has been shown to be optimal to identify the presence of minor depression in postnatal populations [74]. For this purpose and given the variability of cut-off scores to identify antenatal depression in particular, the present study will use a score of 10-12 to identify minor depression and anxiety and $\leq 9$ to identify the absence of perinatal depression and anxiety.

The Clinical Global Impressions - Improvement Scale (CGI-I) [81] is a clinician-rated assessment of the change in participant's symptoms from baseline ranging from 1 (very much improved) to 7 (very much worse). The CGI-I will be administered by graduate students under the supervision of a clinical psychologist and will assess mood, anxiety and global improvements. Participants enrolled in the clinical trial will be asked to rate their own improvement in mood, anxiety and globally at the end of the 12-week RCT phase and again every 4 weeks during the OL phase. The CGI-I has demonstrated high external validity $(r=0.74)$ [82] and is widely used in clinical trials.

\section{Maternal secondary outcome measures}

The Clinical Global Impressions - Severity Scale (CGI-S) [81] is a clinician-rated evaluation of symptom severity ranging from 1 (normal, not ill) to 7 (very severely ill). The CGI-S is commonly used in clinical trials and in a routine clinical setting, has shown to be sensitive to clinical change in diagnostically diverse populations including those diagnosed with depression and anxiety [83]. The CGI-S will be administered by graduate students under the supervision of a clinical psychologist and will assess the severity of mood, anxiety and global functioning.

The Montgomery and Asberg Depression Rating Scale (MADRS) [84] is a 10 item clinician-rated scale that assesses the frequency, severity and duration of depressive symptoms over the previous week. Each item is rated on a 7-point scale ranging from 0 to 5 , with a maximum score of 60. A greater score indicates more severe symptoms. The MADRS demonstrates excellent reliability and good validity [84].The MADRS will be administered by psychology graduate students using the Structured Interview Guide for the Montgomery-Asberg Depression Rating Scale (SIGMA) [85] under the supervision of a clinical psychologist. The SIGMA has demonstrated good to excellent interrater reliability and intraclass correlation $(\mathrm{r}=0.93)$ [85].

Depression Anxiety Stress Scale 21 (DASS21) [86] is a 21 item self-report questionnaire with three, seven item subscales measuring the severity of depression, anxiety and stress, each summing to a maximum score of 21 with elevated scores indicating more severe symptoms. Each item on the DASS-21 is rated on a four point scale ranging from 0 (did not apply to me at all) to 3 (applied to me very much, or most of the time). The DASS-21 provides clinical cut-off scores for each subscale ranging from normal to extremely severe. The DASS- 21 has been widely used in both clinical and non-clinical populations and has demonstrated strong validity and internal consistency ( $\alpha=0.95$ depression, 0.90 anxiety, 0.93 stress, 0.97 total score) [87].

Generalized Anxiety Disorder - 7 item (GAD-7) [88] is a 7 -item self-report measure of generalised anxiety symptoms over the past 2 weeks. Each item is rated on a 4-point scale ranging from 0 (not at all) to 3 (nearly every day). Total scores range from 0 to 21 with higher scores indicating more severe symptoms. The GAD-7 includes the following cut off scores: normal: 0-4; mild: 5-9; moderate: $10-14$ and severe: $15-21$. The GAD-7 has demonstrated good internal consistency and test-retestreliability for diagnosing generalised anxiety disorder in the general population [88, 89]. In perinatal populations, the GAD-7 has yielded a sensitivity of $61.3 \%$ and specificity of $72.7 \%$ at a cut off score of 13 [90].

Perceived Stress Scale (PSS) [91] is a 10 item self-report questionnaire measuring an individual's experience of stress on a 5 -point scale ranging from 0 (never) to 4 (very often). Total scores range from 0 to 40 with higher scores indicating greater levels of stress. The PSS includes cut off scores to indicate the severity of stress: low: 0-13; moderate: 14-26; high: 27-40. The PSS has established testretest reliability and internal consistency $(\alpha=>0.70)$ in culturally diverse populations including pregnancy [92].

Short Form Health Survey - 12 version 1 (SF-12v1) [93] a 12 item self-report questionnaire assessing physical and mental components of health related quality of life over the previous 4 week period. Total scores from each component ranges from 0 to 100 with higher scores indicating better quality of life. The SF-12 has demonstrated good reliability and validity in the general population [93] and for a variety of severe mental health diagnoses [94]. The SF-12 has demonstrated excellent internal consistency in both the first $(\alpha=0.83)$ [95] and third $(\alpha=0.84)$ trimester of pregnancy [96].

Difficulties in Emotion Regulation Scale - Short Form (DERS-SF) [97] is an 18 item self-report questionnaire assessing emotion dysregulation across six subscales which identify lack of awareness, clarity, acceptance, access to strategies, engagement in goal-directed activities 
and ability to manage impulses when experiencing negative emotions. Cronbach's alpha coefficient for each subscale ranged from 0.75 to 0.92 in an adult population [98].

Global Assessment of Functioning (GAF) [99] is a clinician-rated scale included in the DSM-III-R, that considers the severity of social, psychological and occupational functioning of mental health not due to physical or environmental limitations. The GAF is measured on a scale of $0-100$, a higher score indicating a higher level of functioning and includes the following cut-off scores: normal: 91-100; mild: 61-90; moderate: 31-60; severe: $0-30$. The GAF has demonstrated excellent reliability $(\mathrm{ICC}=0.92)[100]$.

The Antidepressant Side-Effect Checklist (ASEC) [101] is a list of 21 symptoms that assesses side effects of the intervention. The ASEC asks participants to indicate the severity of their symptoms on a four-point scale ranging from 0 (absent) to 3 (severe). The ASEC is a self-report assessment of side effects and has been adapted to include further symptoms including rash, itching and numbness, pain, burning or tingling in hands, feet or legs associated with vitamin toxicity. The ASEC is well used and validated in antidepressant drug trials and has been adapted for use with multinutrients. Interrater reliability of each item on the ASEC ranges from 0.55 to 0.89 and internal consistency was adequate ranging from 0.77 to 0.78 [101].

The Pittsburgh Sleep Quality Index (PSQI) [102]) is a 19 item self-report questionnaire that assesses sleep quality, sleep latency, sleep duration and disturbance, habitual sleep efficiency, sleep medication usage and daytime dysfunction over the past month. Each item is rated on a four point scale ranging from 0 to 3 with "poor" sleep indicated at a sum score of five or more [102]. In pregnancy cohorts, the PSQI has demonstrated good construct validity [103] and internal consistency $(\alpha=0.69-0.81)$ [103-105].

Treatment Satisfaction Questionnaire for Medication - 11 (TSQM-11) [106] is an 11 item self-report questionnaire assessing how satisfied participants are with using the multinutrients and the effect of the multinutrients on three domains: effectiveness, convenience and global satisfaction. Each item is rated on a seven point scale ranging from extremely dissatisfied to extremely satisfied with total scores ranging from 0 to 100; higher scores indicating greater satisfaction. The TSQM-11 has demonstrated internal consistency $(\alpha=0.84-0.94)$ and high test-retest reliability $(\mathrm{ICC}=>0.7)[106]$.

Biomarkers of inflammation (interleukin- 4, interleukin- 6 , interleukin- 10 and tumor necrosis factor- $\alpha$ ) and nutrients (vitamin B12, vitamin D, zinc, copper, ferritin, iron, homocysteine, ceruloplasmin, folate) will be analysed from blood samples. A haematology blood count will also be performed.

\section{Maternal covariate outcome measures}

Additional outcomes will be used to assess any mediating or moderating impacts on the treatment outcome.

The Multidimensional Scale of Perceived Social Support (MSPSS) [107] is a 12 item self-report scale measuring the subjective adequacy of social support from family, friends and significant others over the previous 8 week period. Items on the MSPSS are rated on a sevenpoint scale ranging from one to seven with higher scores indicative of greater social support. The MSPSS has demonstrated good internal and test-retest reliability and moderate construct validity [107]. In the pregnant population, the MSPSS has shown excellent internal consistency $(\alpha=0.90-0.92)[104,108]$.

Stressful Life Events Questionnaire (SLEQ) [109] is a 26 item self-report questionnaire assessing the incidence of stressful life events. The scale will be modified for the purposes of this study to exclude the item "you suffered from a mental illness" and include the following items: "You moved house", "You got married", "You had a pet go missing, die or have you had to rehome it". The SLEC was developed for and originally used in a study examining the impact of maternal stress during pregnancy on cognitive development and fearfulness in infancy [109].

Heaviness of Smoking Index (HIS) [110] is a two item self-report questionnaire assessing a person's level of nicotine dependence with higher scores indicating a more severe dependence. For the purposes of using an online assessment tool, the question "Over the past two weeks, have you smoked a cigarette?" will be added to identify whether or not participants have used cigarettes. The HIS has shown to good reliability $(r=0.72-0.70)$ and predictive validity, whereby higher scores have been associated with subsequent quit attempts [111].

The AUDIT - Consumption (AUDIT-C) [112] is a 3 item self-report questionnaire to assess alcohol consumption and identify hazardous drinkers or active alcohol use problems. Items are rated on five-point scale (04) with total scores ranging from 0 to 12 ; higher scores indicating alcohol consumption as a greater risk to safety. A score of three or more has demonstrated the optimal sensitivity (0.66) and specificity (0.94) for identifying alcohol dependency or abuse [112]. In pregnancy populations, the AUDIT-C has shown to be the most sensitive tool for identifying alcohol dependency or abuse (0.71) with excellent sensitivity (0.98) and high specificity (0.85) [113].

Drug Abuse Screening Test - 10 (DAST-10) [114] is a 10 item self-report questionnaire assessing drug use and dependence and has been adapted for the purposes of this study. Participants who identify to have used drugs over 
each two-week period will be asked questions 1, 3 and 9 of the DAST-10, which have demonstrated a Cronbach's alpha of $0.55,0.69$ and 0.78 respectively. Participants will also be asked to identify what substances they have used.

Dietary Screening Tool (DST) [115] is a 24 item selfreport questionnaire that assesses dietary intake and identifies those at nutritional risk. The DST has a total score of 100 with higher scores indicating a healthier dietary pattern. The DST has yielded good sensitivity $(0.83)$ and specificity (0.75). The DST has been adapted to include New Zealand foods for the purposes of this study.

Dietary Inflammatory Index (DII) [116] lists 45 foods and nutrients that positively or negatively affect levels of inflammation. Data from a three-day food diary developed for the purposes of this study will be used to calculate a DII with higher scores indicating greater antiinflammatory effects of foods.

The Helping Alliance Questionnaire (HAQ) is a five item self-report questionnaire developed for the purposes of the study to assess the extent to which the participant has an alliance with the assessor. Each item is rated on a 6 point scale from 0 (strongly disagree) to 5 (strongly agree) with higher scores indicating a greater alliance.

The Dutch Measure for quantification of Treatment Resistance in Depression (DM-TRD) [117] is a refined and extended staging measure of the Maudsley Staging Method [118] used to predict treatment resistance, severity of future depressive symptoms and remission. The DM-TRD will be scored based on outcomes from the SCID-5RV, GAF, Standardised Assessment of Personality - Abbreviated Scale (SAPAS) [119] and questions developed for this study to assess past treatment and therapy.

Anthropometry. Participants height, weight and blood pressure (systolic, diastolic and pulse) will be taken throughout the trial.

\section{Infant measures}

The Brazelton Neonatal Behavioural Assessment Scale (NBAS) [120] is a comprehensive assessment of both neurological integrity and behavioural functioning. The NBAS will be administered by a graduate student to assess the full range of infant neurobehavioral performance (orientation to auditory and visual stimuli) including infant stress (colour changes, tremors, startles), selfsoothing capabilities, states and their organisation within the first 2 weeks after birth. The NBAS is a highly utilized measure in infant studies and has been found to have good internal consistency (Cronbach's $\alpha=0.94$ ) and test-retest reliability [121]. The assessment will be separated into seven clusters for scoring purposes, with each of the NBAS items given a score (ranging from 1 to 9). Higher scores typically indicate better performance, with a lower score typically indicating poorer performance. There are some items however, in which the opposite is the case or where a midpoint score is more optimal. Each participant will be scored on each individual item using the aforementioned scales, and given a total in each of the seven clusters.

The Still-Face Experiment (SFE) [122] is a video-taped observational task used to assess mother-infant interaction. The SFE has been used in a wide range of development studies to assess infant affect, emotional regulation and maternal sensitivity within infant-mother dyads [123126]. The still-face video footage will be coded on a second-by-second basis using the Infant and Caregiver Gaze by Affect/Engagement Phases (ICEP). Behaviours exhibited by mother and baby will be coded into one of nine categories. The nine ICEP categories will be collapsed into the following three categories, both for maternal and child behaviours: negative (negative engagement, hostile/intrusive, withdrawn), neutral (non-infant focused engagement), and positive (social monitor/no vocalizations or neutral vocalizations, social monitor/positive vocalizations, social positive engagement, exaggerated positive engagement). To measure dyadic matching behaviours, the proportion of time in which each mother and infant present with matched/mismatched behaviours during both the play and reunion phases will be calculated.

The Postpartum Bonding Questionnaire (PBQ) [127] is a 25-item self-report questionnaire that assesses maternal attitudes and feelings towards her infant. The questionnaire consists of four subscales that reflect impaired bonding, rejection and anger, anxiety about care and risk of abuse. Each of the subscales utilises a six-point scale, ranging from "always" to "never". Responses to positive questions, such as "I enjoy playing with my baby", will be scored from 0 ("always") to 5 ("never"). Responses to negative questions, such as "I am afraid of my baby", will be reverse scored from 5 ("always") to 0 ("never"). The scores are summated, with a higher score in each of the four subscales indicating problematic bonding. The PBQ has been demonstrated to have acceptable internal consistency (Cronbach's $\alpha=0.76$ ) [128].

Infant Behaviour Questionnaire (Revised) (IBQ-R) [129] is being used to assess infant temperament through a 36-item self-report questionnaire. Questions will be separated into six subscales to measure different temperament dimensions (smiling and laughter, distress to limitation, soothability, activity level, fear, and duration of orientation). They are answered on an eightpoint scale with responses ranging from [1] never to [7] always. There is also a "does not apply" option if the event in question had not occurred at the time point of interest. Responses for each individual subscale are summed, with higher scores indicating greater levels of that temperament dimension. Each of the six subscales of the IBQ has been reported to have acceptable or good internal reliability; smiling and laughter $(\alpha=0.85)$, 
distress to limitation $(\alpha=0.84)$, soothability $(\alpha=0.84)$, activity level $(\alpha=0.73)$, fear $(\alpha=0.80)$ and duration of orienting $(\alpha=0.72)$ [129].

Crying Patterns Questionnaire (CPQ) [130] assesses infant crying patterns and feeding methods over 7 consecutive days and has been widely used in studies assessing crying in infants up to 9 months [130-132]. The questionnaire contains ten questions, providing information on length and frequency of crying episodes and soothing techniques for a typical day within the last week. Length and frequency of crying will be collected in hours or minutes to give a proportion of time spent crying during the day, with higher proportions indicating higher incidence of unsoothability. Frequency of soothing techniques will be scored on a four-point scale, from "never used" to "used repeatedly each day". When compared to data collected using a diary, moderate to good convergence between maternal reports in the CPQ and diaries was found [133].

Ages and Stages Questionnaire: Social-Emotional (ASQ$S E)$ [134]) is a 22-item self-report questionnaire used to assess infants self-regulation, compliance, communication, autonomy, affect and interaction with people. Each question is scored on a three-point scale indicating whether the infant displays the behaviour in question [1] most of the time, [2] sometimes, or [3] never or rarely, and whether or not that particular behaviour is a concern to the parents. Each response will be given a score of $0-10$, with an additional 5 points added if the parents identify a concern, and then summed. Scores can be interpreted as either above or below cut-off score $(2$ month $=35 ; 4 / 6$ month $=45)$ with higher scores indicating problems with behavioural development. The ASQ has been found to have good test-retest reliability, measured as a percentage of agreement between questionnaires, found to be $94 \%$ [134]. Concurrent validity using standardized measures yielded an overall agreement of $85 \%$, with a range of $76-$ $91 \%$. Internal consistency in each of the domains has been found to range between 0.49 to 0.63 when assessed at 4 months [134].

Infant sleep development will be assessed using a $24 \mathrm{~h}$ sleep diary adapted from Henderson [135] that will be completed by a caregiver over 2 consecutive days, once per month.

Birth outcomes and infant anthropometry will be assessed via participant's medical records and will include gestational age, weight, height, head circumference, Apgar score, mode of birth, length of labour, medications during labour/birth and the postnatal period, cord clamping, type of feeding, and vitamin $\mathrm{K}$ injections.

\section{Paternal outcome measures}

Paternal outcomes will be collected to assess potential covariates of a treatment response. Demographic characteristics will be collected and the following measures will be administered to consenting fathers at baseline, 12 weeks RCT, 1 month and 6 months postpartum: EPDS, DASS-21, SF-12 and SLEQ (Fig. 2).

\section{Sample size}

This study aims to recruit 120 participants. In 2014, Christchurch New Zealand had 6575 live births [136]. Assuming at least $12 \%$ of pregnant women meet criteria for depression / anxiety and accounting for 1 in every 100 pregnancies being twin births, approximately 781 women per year would be eligible for the proposed study in Christchurch alone. A placebo-controlled RCT providing multinutrient supplementation to adults with ADHD [73] showed a between groups effect size of 0.64 on a measure of depression. Other RCTs found a between groups effect size of 0.39 on the EPDS when comparing a multinutrient supplement with a placebo in healthy postnatal women [137] and an effect size of 0.88 on depression outcomes from use of a B vitamin complex compared with placebo for participants with major depressive disorder [138]. Based on these findings, to detect a medium to large effect (0.6) using a two-tailed significance level of 0.05 and a power of $0.8,45$ participants per group would be needed. Assuming an attrition rate of $30 \%$ based on the mean dropout rate from the pregnant and postnatal population, 60 participants per group would provide optimal power.

\section{Recruitment}

Participants will be recruited via social media such as Facebook; posters placed in various community settings such as midwifery, radiology and general practices, and via other media opportunities including local magazines, online news articles and the radio. Midwives and obstetricians will also be contacted and offered brochures to hand out to any potentially interested participants. Advertisements will direct prospective participants to register their interest for the study via an online screening questionnaire (http://www.bit.ly/nutrimum).

\section{Allocation \\ Sequence generation}

A research assistant who is not involved in any other aspect of the study will generate the random allocation sequence using the following website: http://www. randomization.com. Allocation will be arranged in a 1:1 sequence using blocks of four.

\section{Allocation concealment}

The research assistant will seal the allocation sequence in an opaque envelope and give it to an independent pharmacist who will pre-pack the study intervention and 


\begin{tabular}{|c|c|c|c|c|c|c|c|c|c|c|c|c|c|c|c|c|c|c|c|c|c|c|}
\hline \multirow[b]{3}{*}{ TIMEPOINT: } & \multicolumn{22}{|c|}{ STUDY PERIOD } \\
\hline & \multirow{2}{*}{\multicolumn{2}{|c|}{\begin{tabular}{c|c|} 
Enrolment & Allocation \\
& 0
\end{tabular}}} & \multicolumn{5}{|c|}{ Post-allocation } & \multirow{2}{*}{$\begin{array}{c}\text { Close-out } \\
12 \mathrm{w}\end{array}$} & \multicolumn{6}{|c|}{ Open-label phase } & \multicolumn{8}{|c|}{ Follow up } \\
\hline & & & $2 \mathrm{w}$ & $4 \mathrm{w}$ & $6 \mathrm{w}$ & $8 \mathrm{w}$ & $10 \mathrm{w}$ & & $2 w$ & $4 \mathrm{w}$ & $6 \mathrm{w}$ & $8 \mathrm{w}$ & $10 \mathrm{w}$ & $12 \mathrm{w}$ & $2 \mathrm{w}$ & $1 \mathrm{~m}$ & $2 \mathrm{~m}$ & $3 \mathrm{~m}$ & $4 \mathrm{~m}$ & $5 \mathrm{~m}$ & $6 \mathrm{~m}$ & $12 \mathrm{~m}$ \\
\hline ENROLMENT: & & & & & & & & & & & & & & & & & & & & & & \\
\hline Eligibility screen & $\mathrm{x}$ & & & & & & & & & & & & & & & & & & & & & \\
\hline Informed consent & $\mathrm{x}$ & & & & & & & & & & & & & & & & & & & & & \\
\hline Allocation & & $\mathrm{x}$ & & & & & & & & & & & & & & & & & & & & \\
\hline \multicolumn{23}{|l|}{ INTERVENTIONS: } \\
\hline Multi-nutrients & & & $\mathrm{x}$ & $\mathrm{x}$ & $\mathrm{x}$ & $\mathrm{x}$ & $\mathrm{x}$ & $\mathrm{x}$ & $\mathrm{x}$ & $\mathrm{x}$ & $\mathrm{x}$ & $\mathrm{x}$ & $\mathrm{x}$ & $\mathrm{x}$ & $\mathrm{x}$ & $\mathrm{x}$ & $\mathrm{x}$ & $\mathrm{x}$ & $\mathrm{x}$ & $\mathrm{x}$ & $\mathrm{x}$ & \\
\hline Active control & & & $\mathrm{x}$ & $\mathrm{x}$ & $\mathrm{x}$ & $\mathrm{x}$ & $\mathrm{x}$ & $\mathrm{x}$ & $\mathrm{x}$ & $\mathrm{x}$ & $\mathrm{x}$ & $\mathrm{x}$ & $\mathrm{x}$ & $\mathrm{x}$ & $\mathrm{x}$ & $\mathrm{x}$ & $\mathrm{x}$ & $\mathrm{x}$ & $\mathrm{x}$ & $\mathrm{x}$ & $\mathrm{x}$ & \\
\hline \multicolumn{23}{|l|}{$\begin{array}{l}\text { ASSESSMENTS } \\
\text { (MATERNAL): }\end{array}$} \\
\hline SCID-5RV & & $\mathrm{x}$ & & & & & & & & & & & & & & & & & & & & \\
\hline DM-TRD (SAPAS) & & $\mathrm{x}$ & & & & & & & & & & & & & & & & & & & & \\
\hline Demographics & $\mathrm{x}$ & & & & & & & & & & & & & & & & & & & & & \\
\hline EPDS & $\mathrm{x}$ & $\mathrm{x}$ & $\mathrm{x}$ & $\mathrm{x}$ & $\mathrm{x}$ & $\mathrm{x}$ & $\mathrm{x}$ & $\mathrm{x}$ & $\mathrm{x}$ & $\mathrm{x}$ & $\mathrm{x}$ & $\mathrm{x}$ & $x$ & $\mathrm{x}$ & $\mathrm{x}$ & $\mathrm{x}$ & $\mathrm{x}$ & $\mathrm{x}$ & $\mathrm{x}$ & $\mathrm{x}$ & $\mathrm{x}$ & $\mathrm{x}$ \\
\hline CGI-S & & $\mathrm{x}$ & & $\mathrm{x}$ & & $\mathrm{x}$ & & $\mathrm{x}$ & & $\mathrm{x}$ & & $\mathrm{x}$ & & $\mathrm{x}$ & & $\mathrm{x}$ & & & & & $\mathrm{x}$ & \\
\hline DASS-21 & & $\mathrm{x}$ & $\mathrm{x}$ & $\mathrm{x}$ & $\mathrm{x}$ & $\mathrm{x}$ & $\mathrm{x}$ & $\mathrm{x}$ & $\mathrm{x}$ & $\mathrm{x}$ & $\mathrm{x}$ & $\mathrm{x}$ & $\mathrm{x}$ & $\mathrm{x}$ & & $\mathrm{x}$ & & & & & $\mathrm{x}$ & $\mathrm{x}$ \\
\hline GAD-7 & & $\mathrm{x}$ & $\mathrm{x}$ & $\mathrm{x}$ & $\mathrm{x}$ & $\mathrm{x}$ & $\mathrm{x}$ & $\mathrm{x}$ & $\mathrm{x}$ & $\mathrm{x}$ & $\mathrm{X}$ & $\mathrm{x}$ & $\mathrm{x}$ & $\mathrm{x}$ & & $\mathrm{x}$ & & & & & $\mathrm{x}$ & $\mathrm{x}$ \\
\hline ASEC & & $\mathrm{x}$ & $\mathrm{x}$ & $\mathrm{x}$ & $\mathrm{x}$ & $\mathrm{x}$ & $\mathrm{x}$ & $\mathrm{x}$ & $\mathrm{x}$ & $\mathrm{x}$ & $\mathrm{x}$ & $\mathrm{x}$ & $\mathrm{x}$ & $\mathrm{x}$ & & & & & & & 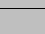 & \\
\hline HSI & & $\mathrm{x}$ & $\mathrm{x}$ & $\mathrm{x}$ & $\mathrm{x}$ & $\mathrm{x}$ & $\mathrm{x}$ & $\mathrm{x}$ & $\mathrm{x}$ & $\mathrm{x}$ & $\mathrm{x}$ & $\mathrm{x}$ & $\mathrm{x}$ & $\mathrm{x}$ & & $\mathrm{x}$ & & & & & $\mathrm{x}$ & $\mathrm{x}$ \\
\hline AUDIT & & $\mathrm{x}$ & $\mathrm{x}$ & $\mathrm{x}$ & $\mathrm{x}$ & $\mathrm{x}$ & $\mathrm{x}$ & $\mathrm{x}$ & $\mathrm{x}$ & $\mathrm{x}$ & $\mathrm{x}$ & $\mathrm{x}$ & $\mathrm{x}$ & $\mathrm{x}$ & & $\mathrm{x}$ & & & & & $\mathrm{x}$ & $\mathrm{x}$ \\
\hline DAST 10 & & $\mathrm{x}$ & $\mathrm{x}$ & $\mathrm{x}$ & $\mathrm{x}$ & $\mathrm{x}$ & $\mathrm{x}$ & $\mathrm{x}$ & $\mathrm{x}$ & $\mathrm{x}$ & $\mathrm{x}$ & $\mathrm{x}$ & $\mathrm{x}$ & $\mathrm{x}$ & & $\mathrm{x}$ & & & & & $\mathrm{x}$ & $\mathrm{x}$ \\
\hline GAF & & $\mathrm{x}$ & & $\mathrm{x}$ & & $\mathrm{x}$ & & $\mathrm{x}$ & & $\mathrm{x}$ & & $\mathrm{x}$ & & $\mathrm{x}$ & & $\mathrm{x}$ & & & & & $\mathrm{x}$ & \\
\hline MADRS & & $\mathrm{x}$ & & $\mathrm{x}$ & & $\mathrm{x}$ & & $\mathrm{x}$ & & $\mathrm{x}$ & & $\mathrm{x}$ & & $\mathrm{x}$ & & $\mathrm{x}$ & & & & & $\mathrm{x}$ & \\
\hline PSS & & $\mathrm{x}$ & & $\mathrm{x}$ & & $\mathrm{x}$ & & $\mathrm{x}$ & & $\mathrm{x}$ & & $\mathrm{x}$ & & $\mathrm{x}$ & & $\mathrm{x}$ & & & & & $\mathrm{x}$ & $\mathrm{x}$ \\
\hline PSQI & & $\mathrm{x}$ & & $\mathrm{x}$ & & $\mathrm{x}$ & & $\mathrm{x}$ & & $\mathrm{x}$ & & $\mathrm{x}$ & & $\mathrm{x}$ & & $\mathrm{x}$ & & & & & $\mathrm{x}$ & $\mathrm{x}$ \\
\hline SF-12 & & $\mathrm{x}$ & & $\mathrm{x}$ & & $\mathrm{x}$ & & $\mathrm{x}$ & & $\mathrm{x}$ & & $\mathrm{x}$ & & $\mathrm{x}$ & & $\mathrm{x}$ & & & & & $\mathrm{x}$ & $\mathrm{x}$ \\
\hline DERS-SF & & $\mathrm{x}$ & & $\mathrm{x}$ & & & & & & $\mathrm{x}$ & & $\mathrm{x}$ & & $\mathrm{x}$ & & $\mathrm{x}$ & & & & & $\mathrm{x}$ & $\mathrm{x}$ \\
\hline MSPSS & & $\mathrm{x}$ & & $\mathrm{x}$ & & $\mathrm{x}$ & & $\mathrm{x}$ & & $\mathrm{x}$ & & $\mathrm{x}$ & & $\mathrm{x}$ & & $\mathrm{x}$ & & & & & $\mathrm{x}$ & $\mathrm{x}$ \\
\hline SLEC & & $\mathrm{x}$ & & & & & & $\mathrm{x}$ & & & & & & & & & & & & & $\mathrm{x}$ & $\mathrm{x}$ \\
\hline DST & & $\mathrm{x}$ & & & & & & $\mathrm{x}$ & & & & & & & & $\mathrm{x}$ & & & & & $\mathrm{x}$ & $\mathrm{x}$ \\
\hline DII & & $x$ & & & & & & $\mathrm{x}$ & & & & & & & & & & & & & & \\
\hline Phlebotomy & & $\mathrm{x}$ & & & & & & $\mathrm{x}$ & & & & & & & & & & & & & & \\
\hline Faecal sample & & $\mathrm{x}$ & & & & & & $\mathrm{x}$ & & & & & & & $\mathrm{x}$ & & & & & & & \\
\hline CGIII & & & & $\mathrm{x}$ & & $\mathrm{x}$ & & $\mathrm{x}$ & & $\mathrm{x}$ & & $\mathrm{x}$ & & $\mathrm{x}$ & & $\mathrm{x}$ & & & & & $\mathrm{x}$ & \\
\hline TSQM-11 & & & & & & & & $\mathrm{x}$ & & $\mathrm{x}$ & & $\mathrm{x}$ & & $\mathrm{x}$ & & & & & & & & \\
\hline \multicolumn{23}{|l|}{$\begin{array}{l}\text { ASSESSMENTS } \\
\text { (INFANT): }\end{array}$} \\
\hline Birth Outcomes & & & & & & & & & & & & & & & $\mathrm{x}$ & & & & & & & \\
\hline Anthropometry & & & & & & & & & & & & & & & $\mathrm{x}$ & & & & & & & \\
\hline Faecal sample & & & & & & & & & & & & & & & $\mathrm{x}$ & & & & & & & \\
\hline NBAS & & & & & & & & & & & & & & & $\mathrm{x}$ & & & & & & & \\
\hline PBQ & & & & & & & & & & & & & & & & $\mathrm{x}$ & $\mathrm{x}$ & & $\mathrm{x}$ & & $\mathrm{x}$ & \\
\hline \begin{tabular}{|l|l} 
Infant Sleep Diary \\
\end{tabular} & & & & & & & & & & & & & & & & $\mathrm{x}$ & $\mathrm{x}$ & $\mathrm{x}$ & $\mathrm{x}$ & $\mathrm{x}$ & $\mathrm{x}$ & \\
\hline CPQ & & & & & & & & & & & & & & & & $\mathrm{x}$ & $\mathrm{x}$ & $\mathrm{x}$ & $\mathrm{x}$ & $\mathrm{x}$ & $\mathrm{x}$ & \\
\hline SFE & & & & & & & & & & & & & & & & & $\mathrm{x}$ & & & & & \\
\hline IBQ-R & & & & & & & & & & & & & & & & & & & $\mathrm{x}$ & & $\mathrm{x}$ & \\
\hline ASQ-SE & & & & & & & & & & & & & & & & & & & $\mathrm{x}$ & & $\mathrm{x}$ & \\
\hline & $\begin{array}{l}\text { RVV: Struct } \\
\text { Edinhurgh } \\
\text { ressant Sid } \\
\text { S.: Montgor } \\
\text { Short Form } \\
\text { sions Scale } \\
\text { our Questio }\end{array}$ & $\begin{array}{l}\text { ured Clinical } \\
\text { Postratat Dep } \\
\text { e Effects Chece } \\
\text { nere }\end{array}$ & & 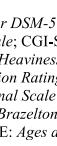 & $\begin{array}{l}\text { Neonatal } \\
\text { Id Stages }\end{array}$ & $\begin{array}{l}\text { usessmen } \\
\text { usestionn }\end{array}$ & : ale, Pr & 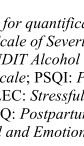 & & 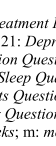 & $\begin{array}{l}\text { alre; } \\
\text { aths. } \\
\text { the }\end{array}$ & 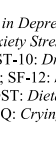 & & 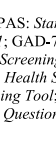 & 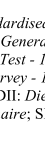 & 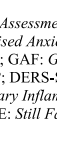 & 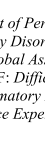 & 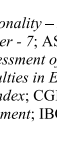 & 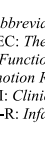 & $\begin{array}{l}\text { d Scale; } \\
\text { ng; } \\
\text { ulation } \\
\text { Illobal }\end{array}$ & & \\
\hline 2 Partıcı & t flor & ough & & in & & & & & & & & & & & & & & & & & & \\
\hline
\end{tabular}

active control accordingly. The pharmacist will seal treatment allocation cards (active or control) in the numbered opaque envelopes in accordance with the allocation sequence. The envelopes will be returned to the study site and stored in a locked drawer. This process ensures that the blind remains for all 
participants should the blind need to be broken for an individual participant during the course of the trial.

\section{Implementation}

Participants will be enrolled by the research coordinator (H.B) and will be assigned the next sequential number.

\section{Blinding}

Both participants and researchers including the data analyst will be blinded to the group assignment of each individual. Following analysis of the primary and secondary outcomes, the blind will be broken and participants will be informed of their treatment allocation. Breaking of the blind will be assessed on a case-by-case basis and will first be discussed with the trial physician.

\section{Procedure}

\section{Screening assessment}

The online screening questionnaire will assess the eligibility of women who register their interest to participate in the study. Women who do not meet the eligibility criteria for the study will be sent an email encouraging them to speak with their lead maternity carer and consult with listed support services if needed. Women who are eligible from the screening will be contacted and asked further questions before inviting them to visit the research site to provide informed consent. Should a participant not enrol in the trial for more than 2 weeks after the initial screening or register their interest to participate in the study before 12 weeks gestation, they are required to complete a second screening to ensure they are eligible to participate in the study.

\section{Informed consent}

Eligible participants are sent the trial information sheet (via email or post) prior to attending the consent appointment. Researchers (HB and SC) will obtain written consent from women willing to participate in the trial following an informed discussion.

\section{Baseline assessment}

Following informed consent, a baseline appointment will be arranged during which participants will be asked to complete a series of online questionnaires and have their weight and blood pressure assessed. The appointment also involves an assessment of current and past mood and anxiety disorders using the Structured Clinical Interview for DSM-5, Research Version (SCID-5RV) [139]. The Dutch Measure for Quantification of Treatment Resistance in Depression (DMQTR) [117] will be utilized to predict treatment resistance. The DMQTR will be scored based on outcomes from the SCID-5RV, Global Assessment of Functioning from Axis V of the Diagnostic and Statistical Manual of Mental Disorders,
Fourth Edition Text Revision [99], Standardised Assessment of Personality - Abbreviated Scale [119] and questions regarding treatment and therapy.

Participants' partners who agree to participate in the study will provide consent separately. Participants will be given their first bottle of capsules and a capsule organizer containing vanilla sachets in each compartment in order to improve adherence and ensure consistency across treatment arms in smell. They will also be given veral and written instructions on how to take the capsules and titrate the dose over the first week. A blood form and instructions for fasting will also be given to participants who consent to provide blood samples. Participants who provide blood samples will be advised to start taking the capsules the day following blood withdrawal.

\section{Trial phase and follow up}

Once enrolled in the trial, participants will be required to visit the research site every 4 weeks throughout both the RCT and open label phase until their infant is born. At these visits, participants will complete assessments, collect a new bottle of capsules and return any unused capsules. The next appointment will be scheduled in order to promote participant retention. Two weeks after each visit, participants will be required to complete an online questionnaire at home that assesses mood, side effects and any adverse events. Participants will meet with the researchers for follow up assessments either at the university, at the participant's home or if possible, over the phone (some participants may find it difficult to travel independently following a caesarean section). Assessments will occur at 1, 6 and 12 months postpartum for all participants including those who discontinue in the trial or deviate from the intervention protocol.

For each visit to the research site, participants will be given a NZD\$10 petrol voucher to reimburse travel expenses. A hamper package consisting of products both bought and independently donated will also be provided to participants who complete the RCT phase of the trial in order to congratulate them on the birth of their infant and thank them for their participation. The companies who donate products are not in any other way affiliated with this research.

At the end of the open label phase, participants will decide whether or not they wish to continue taking the treatment and will accordingly be supplied with information on how to obtain the multinutrients.

\section{Data management}

All data is collected, entered and coded by H.B and S.C and will be stored on a password protected computer 
system at the University of Canterbury. Electronic information will be gathered using a password protected web-based data collection system (www.canterbury.qualtrics.com) and hard copies will be stored in secure filing cabinets, behind two locked doors at the University of Canterbury.

\section{Data analysis}

Demographic characteristics will be compared across the treatment groups using independent samples $t$-tests in order to test for potential failures of randomization.

For the primary outcomes (EPDS and CGI-I scores), the repeated measures of the outcome variables will be modelled using generalized linear mixed effects regression models using Stata 15 [140]. These models will permit the testing of differences between the multinutrient group and the active control group over the course of the trial. In the case of the EPDS, baseline scores will be used as a covariate factor. For secondary outcomes (e.g. MADRS, DASS), linear mixed effects models will also be used.

The pooled mean scores (and standard deviations) over the course of the trial on each of the primary outcomes will be used to compute estimates of effect size (Cohen's $d$ ). Clinical significance between groups will be identified by a minimum of a three point difference in EPDS scores. Clinical significance within groups will be identified by a four point change on the EPDS as described by Matthey [141]. A clinical significant change will be categorised as the following: 'Recovered': participants who move from a score of 13 or more at baseline to 11 or less following treatment and whose score has reduced by four points; 'Improved': participants whose baseline score reduces by four points post treatment but is still above 13 or more; 'Deteriorated': participants whose baseline score increases by four points post treatment; 'No change': participants whose pre-post score is less than a four point change.

All data will be analysed on an intention-to-treat basis using the last observation carried forward method and as such will include all participants' data regardless of treatment compliance. Treatment adherence will be measured by the total number of capsules consumed throughout the trial phases. Only participants who consume $70 \%$ or more of the total number of capsules will be considered adherent to the treatment. A per-protocol analysis, which excludes participants with protocol violations (e.g. drop out, non-adherence to treatment consumption) will be performed on the primary outcomes (EPDS and CGI-I) in order to compare differences in treatments responses between participants who were adherent with the treatment and those who discontinued participation or were non-adherent. Outcomes from the open label phase will be compared to the group outcomes from the week 12 observation of the RCT phase using generalised linear mixed effects regression models taking into account participants self-reported use of micronutrients.

To assess the effect of the multinutrient intervention has on infant development, we will compare those infants exposed to the multinutrients versus those infants not exposed to the multinutrients on emotional, cognitive and physical development. Length of exposure to the multinutrients (due to the RCT phase and varying starting points during gestation) and score on the EPDS will also be considered as continuous variables in considering infant outcomes. Hierarchical regression analysis will be run using Stata 15 in order to identify if perinatal/postpartum depression and multinutrient exposure are predictors of improved self-regulation of the infant across the various time points. Descriptive statistics for each participant will be used to compare demographic characteristics between the treatment groups to allow any differences to be controlled.

\section{Data monitoring}

Trial progress and adverse events will be reported and assessed by the Southern Human and Disabilities Ethics Committee every 12 months. The trial will be terminated if serious adverse effects known to be caused by the nutrients occur and/or if there is no evidence of any improvement in symptoms in the first 40 participants who complete the RCT phase of the trial. An interim analysis will not be conducted.

\section{Safety monitoring and reporting}

A protocol is in place to respond to situations in which a participant reports adverse symptoms of either a physical or psychological nature throughout the duration of the trial. Adverse events and side effects will be monitored within the first week of the trial via telephone and fortnightly thereafter via a questionnaire asking participants to identify any new medical problems, infections, hospitalizations (excluding birth) and medication and supplement use. Participants will be advised to contact the study investigators if they are concerned about any increases in physical or psychological symptoms.

Should a participant's psychological symptoms worsen, they will be instructed to contact the study investigators who in discussion with the participant, may refer them to their General Practitioner (GP), psychiatric emergency services or may decide to offer the open label option earlier if there is a worsening in symptoms during the RCT phase. If a participant's psychological state deteriorates to a clinically significant degree during the trial, the investigators will discuss with the participant the possibility of 
Table 2 Trial registration data

\begin{tabular}{l} 
Data category \\
\hline Primary registry and trial \\
identification number \\
Date of registration in primary \\
registry \\
Secondary identifying numbers \\
Source(s) of monetary or material \\
support
\end{tabular}

Trial information

Australian and New Zealand Clinical Trials Registry; ACTRN12617000354381

8 March 2017

Universal Trial Number (UTN): U1111-1189-4070

Hardy Nutritionals, Department of Psychology Research Funds, University of Canterbury; University of Canterbury Foundation; Foundation for Excellence in Mental Health Care; The Nurture Foundation for Reproductive Research; St George's Hospital, NZ, Canterbury Medical Research Foundation,

Primary sponsor Prof Julia Rucklidge

Secondary sponsor(s)

Prof Roger Mulder, Dr. Jacqueline Henderson, Prof Martin Kennedy, Dr. Kyle Nash, Dr. Lesley Dixon, A/P Joseph Boden, Hayley Bradley

Contact for public enquiries Hayley Bradley, hayley.bradley@pg.canterbury.ac.nz

Contact for scientific enquiries

Prof Julia Rucklidge, julia.rucklidge@canterbury.ac.nz

Public title

A multinutrient intervention for pregnant women experiencing symptoms of depression and anxiety.

Scientific title

Countries of recruitment

An investigation examining the efficacy and safety of a multinutrient intervention on symptoms of antenatal depression and anxiety in pregnant women who are symptomatic: A double blind, randomized, controlled trial.

Health condition(s) or problem(s) studied

New Zealand

Depression, anxiety

Interventions

Intervention: Daily Essential Nutrients (12 capsules per day)

Active control: lodine and Riboflavin (12 capsules per day)

Key inclusion and exclusion criteria Ages eligible for study: $\geq 16$ years; Sexes available for study: femaleAccepts healthy volunteers: no

Inclusion criteria: women aged 16 years and over; 12-24 weeks gestation; low risk singleton pregnancy; free from psychiatric medication for four weeks; score of 13 or more on the Edinburgh Postnatal Depression Scale (EPDS); deemed reliable and compliant with the protocol

Exclusion criteria: regular vomiting; high risk pregnancy; significant pregnancy complications; known foetal abnormalities; serious current or historical medical condition; known allergy to the ingredients of the intervention; known metabolic condition such as Wilson's disease, hemochromatosis.; untreated or unstable thyroid disease; known neurological disorder; desire to continue taking prenatal supplements that either exceed the upper limit or are not required for medical purposes (decisions discussed and made on a case-by-case basis)

Study type Interventional

Allocation: randomised, parallel assignment; Masking: blinding of people taking and administering the treatment, assessing the outcomes and analysing the results / data

Primary purpose: treatment

Date of first enrolment

12 April 2017

Target sample size

120

Recruitment status

Recruiting

Primary outcome(s)

Depression and anxiety; Edinburgh Postnatal Depression Scale (time points: screening, baseline, every two weeks until birth and at 1 month and 6 months postpartum)

Symptom improvement; Clinical Global Impressions Scale - Improvement (time points: baseline, every four weeks until birth and at 1 month and 6 months postpartum)

Key secondary outcomes

Depression; The Montgomery and Asberg Depression Rating Scale (time points: baseline, every four weeks until birth and at 1 month and 6 months postpartum)

Anxiety; Generalized Anxiety Disorder - 7 (time points: baseline, every two weeks until birth and at 1 month and 6 months postpartum)

Depression, Anxiety, Stress; Depression, Anxiety, Stress Scale - 21 (time points: baseline, every two weeks until birth and at 1 month and 6 months postpartum)

Sleep quality; The Pittsburgh Sleep Quality Index (time points: baseline, every four weeks until birth and at 1 month and 6 months postpartum)

Quality of life; Short Form Health Survey - 12 (time points: baseline, every four weeks until birth and at 1 month and 6 months postpartum)

Emotion dysregulation; Difficulties in Emotion Regulation Scale - Short Form (time points: baseline, every four 
Table 2 Trial registration data (Continued)

\begin{tabular}{ll}
\hline Data category & Trial information \\
\hline & weeks until birth and at 1 month and 6 months postpartum) \\
& Side effects; Antidepressant Side-Effect Checklist, (time points: baseline, every two weeks until birth and at 1 \\
& month and 6 months postpartum) \\
& Plasma nutrient levels (vitamin C, vitamin B12, vitamin D, copper, zinc, iron and homocysteine) (time points: \\
& baseline and 12 weeks) \\
& Inflammatory biomarkers (interleukin - 6, tumor necrosis factor - alpha, interleukin-4 and interleukin-10) (time \\
& points: baseline and 12 weeks) \\
& Anxiety related endophenotypes and neurophysiological markers; Electroencephalography (time points: baseline \\
& and 12 weeks) \\
& Microbiome; faecal samples (time points: baseline and 12 weeks) \\
\hline
\end{tabular}

withdrawing from the study, or may decide that the participant should be withdrawn. If withdrawn, participants will be referred to health care services as appropriate. Participants will also be informed that they can withdraw from the trial for any reason at any time without penalty. Should a participant withdraw or be withdrawn from the trial or be lost to follow up, relevant details will be documented. In the event of a physical or psychiatric emergency, participants will be advised to contact emergency services or visit the emergency department immediately. Participants incurring a physical injury as a result of participating in the trial will be eligible for compensation from Accident Compensation Corporation (ACC) under the Accident Compensation Act 2001 [142].

Serious adverse events will be categorized according to the New Zealand Ministry of Health guidelines. According to the New Zealand Ministry of Health, a serious adverse event is considered to occur at any dose that results in death, or is life threatening, or requires inpatient hospitalization or prolongs hospitalization, or results in persistent or significant disability or incapacity, or is a congenital anomaly or birth defect [143]. Any serious adverse events will be recorded and reported annually to the Southern Health and Disability Ethics Committee, New Zealand.

\section{Study integrity}

This study has received ethical approval by the Southern Human and Disabilities Ethics Committee (Reference: 16/STH/187) on 3 February 2017 and the Standing Committee on Therapeutic Trials (Reference: 16/SCOTT/131) on 7 February 2017. The study has also received approval from the New Zealand College of Midwives and the Human Ethics Committee and Ngā Tahu Consultation and Engagement Group at the University of Canterbury. The Universal Trial Number (UTN) for this study is U1111-1189-4070. Any protocol amendments will be raised with the ethics committee for approval and approved changes will be updated on the trial registry and in the trial protocol. Protocol version: 06; 23 January 2019.

This trial was prospectively registered in the Australian and New Zealand Clinical Trials Registry (ANZCTR) on 8 March 2017 (Trail ID: ACTRN12617000354381) (Table 2).

All participants will be required to provide informed consent before entry into the study and any personal details will be stored in locked filing cabinets and password protected databases. Study records and the final trial dataset will identify participants by their ID number only. Only the investigators affiliated with this trial will have access to the final dataset. The trial results will be released to participants and health professionals and other referring agents including a mothers and babies psychiatric service and obstetric and midwifery practices. Findings will also be published in peer-reviewed journals and disseminated via social media and other media outlets.

\section{Discussion}

Pregnant women suffering from depression and anxiety have limited treatment options available for their symptoms. This RCT with an open label phase and naturalistic follow up has been designed to assess the efficacy and safety of a multinutrient formula on symptoms of mood and anxiety during antenatal period and the impact in-utero exposure to multinutrients may have on infant development. Should the nutrients be shown to be safe and beneficial, then we begin to build an evidence base of an alternative treatment option for women suffering from antenatal depression and anxiety. The findings may also improve the short and long-term outcomes not only for the mother and the infant but also for their families and community.

\section{Abbreviations}

RCT: Randomised controlled trial; OL: Open label; DEN: Daily Essential Nutrients; CES-D: Centre for Epidemiologic Studies - Depression Scale; ADHD: Attention deficit hyperactivity disorder; ASD: Autism spectrum disorder; EPDS: Edinburgh Postnatal Depression Scale; CGI-I: Clinical Global Impressions - Improvement Scale; CGI-S: Clinical Global Impressions Scale Severity Scale; SCID-5RV: Structured Clinical Interview for DSM-5 (research 
version); GAF : Global Assessment of Functioning; MADRS: Montgomery and Asberg Depression Rating Scale; DM-TRD: The Dutch Measure for Quantification of Treatment Resistance in Depression; SAPAS: Standardised Assessment of Personality - Abbreviated Scale; DASS-21: Depression, Anxiety, Stress Scale - 21; GAD-7: Generalized Anxiety Disorder - 7; PSS: Perceived Stress Scale; PSQI: Pittsburgh Sleep Quality Index; SF-12: Short form Health Survey - 12; DERS-SF: Difficulties in Emotion Regulation Scale - Short Form; ASEC: Antidepressant Side-Effect Checklist;; MSPSS: Multidimensional Scale of Perceived Social Support; SLEQ: Stressful Life Events Questionnaire; HSI: Heaviness of Smoking Index; AUDIT: AUDIT Alcohol Consumption Questions; DAST-10: Drug Abuse Screening Test - 10; DST: Dietary Screening Tool; DII: Dietary Inflammatory Index; TSQM-11: Treatment Satisfaction Questionnaire for Medication - 11; NBAS: Brazelton Neonatal Assessment Scale; PBQ: Postpartum Bonding Questionnaire; CPQ: Crying Patterns Questionnaire; SFE: Still Face Experiment; IBQ-R: Infant Behaviour Questionnaire - Revised; ASQ-SE: Ages and Stages Questionnaire: Social and Emotional; ACC: Accident Compensation Corporation; UTN: Universal Trial Number

\section{Acknowledgements}

Not applicable.

\section{Authors' contributions}

$\mathrm{HAB}$ and $\mathrm{SC}$ are involved in the study design, recruitment of participants and data collection and management. JJR is involved in the study design, recruitment, data collection and providing clinical oversight of the trial. RTM is involved in the study design and providing medical oversight of the trial. JMTH is involved in study design and provides expertise on infant and child development. LD is involved in the design of the study, supporting recruitment of participants and providing obstetric advice and support. JB is involved in the analysis and interpretation of the trial outcomes. All authors have shared in the writing of the study protocol and have read and approved the final manuscript.

\section{Authors' information}

HAB and SC are graduate students. JJR is a registered clinical psychologist providing supervision to HAB and SC. RTM is a registered psychiatrist. JMTH is a lecturer in developmental psychology, LD is a registered midwife, JB is an experimental social psychologist and statistician.

\section{Funding}

This research has received funding from the Department of Psychology Research Funds, University of Canterbury; University of Canterbury Foundation; Foundation for Excellence in Mental Health Care; The Nurture Foundation for Reproductive Research; St George's Hospital, New Zealand, Canterbury Medical Research Foundation and The Waterloo Foundation.

\section{Availability of data and materials}

Not applicable.

\section{Ethics approval and consent to participate}

This study received ethical approval by the Southern Human and Disabilities Ethics Committee (Reference: 16/STH/187) and the Standing Committee on Therapeutic Trials (Reference: 16/SCOTT/131). All participants are required to provide informed consent before entry into the study.

\section{Consent for publication}

Not applicable.

\section{Competing interests}

The authors declare that they have no competing interests. Funding sources provide monetary donations only; they are not involved in any other aspect of the study.

\section{Author details}

${ }^{1}$ School of Psychology, Speech and Hearing, University of Canterbury, Private Bag 4800, Christchurch 8041, New Zealand. 'Department of Psychological Medicine, University of Otago, Christchurch, New Zealand. ${ }^{3}$ New Zealand College of Midwives, Christchurch, New Zealand.
Received: 26 November 2019 Accepted: 28 July 2020

Published online: 25 August 2020

\section{References}

1. Mathers CD, Loncar D. Projections of global mortality and burden of disease from 2002 to 2030. PLoS Med. 2006;3(11):e442.

2. Gavin NI, Gaynes BN, Lohr KN, Meltzer-Brody S, Gartlehner G, Swinson T. Perinatal depression: a systematic review of prevalence and incidence. Obstet Gynecol. 2005;106(5, Part 1):1071-83.

3. Giardinelli L, Innocenti A, Benni L, Stefanini M, Lino G, Lunardi C, et al. Depression and anxiety in perinatal period: prevalence and risk factors in an Italian sample. Arch Womens Ment Health. 2012;15(1):21-30.

4. Andersson L, Sundström-Poromaa I, Bixo M, Wulff M, Bondestam K, Åström M. Point prevalence of psychiatric disorders during the second trimester of pregnancy: a population-based study. Am J Obstet Gynecol. 2003;189(1):148-54.

5. Signal TL, Paine S-J, Sweeney B, Muller D, Priston M, Lee K, et al. The prevalence of symptoms of depression and anxiety, and the level of life stress and worry in New Zealand Māori and non-Māori women in late pregnancy. Aust N Z J Psychiatry. 2016;51(1):168-76.

6. Waldie KE, Peterson ER, D'Souza S, Underwood L, Pryor JE, Carr PA, et al. Depression symptoms during pregnancy: evidence from growing up in New Zealand. J Affect Disord. 2015;186:66-73.

7. Association AP. Diagnostic and statistical manual of mental disorders: DSM5. Washington, D.C: American Psychiatric Association; 2013.

8. Grote NK, Bridge JA, Gavin AR, Melville JL, lyengar S, Katon WJ. A metaanalysis of depression during pregnancy and the risk of preterm birth, low birth weight, and intrauterine growth restriction. Arch Gen Psychiatry. 2010; 67(10):1012-24.

9. Ciesielski TH, Marsit CJ, Williams SM. Maternal psychiatric disease and epigenetic evidence suggest a common biology for poor fetal growth. BMC Pregnancy Childbirth. 2015;15(1):192.

10. Davalos DB, Yadon CA, Tregellas HC. Untreated prenatal maternal depression and the potential risks to offspring: a review. Arch Womens Mental Health. 2012;15(1):1-14.

11. Grigoriadis S, VonderPorten EH, Mamisashvili L, Tomlinson G, Dennis C-L, Koren $\mathrm{G}$, et al. The impact of maternal depression during pregnancy on perinatal outcomes: a systematic review and meta-analysis. J Clin Psychiatry. 2013;74(4):e321-e41.

12. Stroustrup A, Hsu H-H, Svensson K, Schnaas L, Cantoral A, González MS, et al. Toddler temperament and prenatal exposure to lead and maternal depression. Environ Health. 2016;15(1):71.

13. Szegda K, Markenson G, Bertone-Johnson ER, Chasan-Taber L. Depression during pregnancy: a risk factor for adverse neonatal outcomes? A critical review of the literature. J Matern Fetal Neonatal Med. 2014;27(9):960-7.

14. Jarde A, Morais M, Kingston D, Giallo R, MacQueen GM, Giglia L, et al. Neonatal outcomes in women with untreated antenatal depression compared with women without depression: a systematic review and metaanalysis. JAMA Psychiatry. 2016;73(8):826-37.

15. Letourneau NL, Dennis C-L, Benzies K, Duffett-Leger L, Stewart M, Tryphonopoulos PD, et al. Postpartum depression is a family affair: addressing the impact on mothers, fathers, and children. Issues Ment Health Nurs. 2012;33(7):445-57.

16. Stein A, Pearson RM, Goodman SH, Rapa E, Rahman A, McCallum M, et al. Effects of perinatal mental disorders on the fetus and child. Lancet. 2014; 384(9956):1800-19.

17. Malhi GS, Bassett $D$, Boyce $P$, Bryant R, Fitzgerald PB, Fritz K, et al. Royal Australian and new Zealand College of Psychiatrists clinical practice guidelines for mood disorders. Aust N Z J Psychiatry. 2015;49(12):1087-206.

18. Boath E, Bradley E, Henshaw C. Women's views of antidepressants in the treatment of postnatal depression. J Psychosom Obstet Gynecol. 2004;25(34):221-33.

19. Bonari L, Koren G, Einarson T, Jasper J, Taddio A, Einarson A. Use of antidepressants by pregnant women: evaluation of perception of risk, efficacy of evidence based counseling and determinants of decision making. Arch Womens Ment Health. 2005;8(4):214-20.

20. Lemon E, Vanderkruik R, Arch JJ, Dimidjian SA. Treating anxiety during pregnancy: patient concerns about pharmaceutical treatment. Matern Child Health J. 2020;24(4):439-46.

21. Grigoriadis S, VonderPorten EH, Mamisashvili L, Roerecke M, Rehm J, Dennis $C-L$, et al. Antidepressant exposure during pregnancy and congenital 
malformations: is there an association? A systematic review and metaanalysis of the best evidence. J Clin Psychiatry. 2013;74(4):e293-308.

22. Myles N, Newall H, Ward H, Large M. Systematic meta-analysis of individual selective serotonin reuptake inhibitor medications and congenital malformations. Aust N Z J Psychiatry. 2013;47(11):1002-12.

23. Galbally M, Lewis AJ, Lum J, Buist A. Serotonin discontinuation syndrome following in utero exposure to antidepressant medication: prospective controlled study. Aust N Z J Psychiatry. 2009;43(9):846-54.

24. Grigoriadis S, VonderPorten EH, Mamisashvili L, Eady A, Tomlinson G, Dennis $C-L$, et al. The effect of prenatal antidepressant exposure on neonatal adaptation: a systematic review and meta-analysis. J Clin Psychiatry. 2013; 74(4):309-20.

25. Byatt N, Deligiannidis KM, Freeman MP. Antidepressant use in pregnancy: a critical review focused on risks and controversies. Acta Psychiatr Scand. 2013;127(2):94-114.

26. De Vera MA, Bérard A. Antidepressant use during pregnancy and the risk of pregnancy-induced hypertension. Br J Clin Pharmacol. 2012;74(2):362-9.

27. Hanley GE, Brain U, Oberlander TF. Infant developmental outcomes following prenatal exposure to antidepressants, and maternal depressed mood and positive affect. Early Hum Dev. 2013;89(8):519-24.

28. Misri S, Reebye P, Kendrick K, Carter D, Ryan D, Grunau RE, et al. Internalizing behaviors in 4-year-old children exposed in utero to psychotropic medications. Am J Psychiatr. 2006;163(6):1026-32.

29. Oberlander TF, Reebye P, Misri S, Papsdorf M, Kim J, Grunau RE. Externalizing and attentional behaviors in children of depressed mothers treated with a selective serotonin reuptake inhibitor antidepressant during pregnancy. Arch Pediatr Adolesc Med. 2007;161(1):22-9.

30. Pedersen LH, Henriksen T, Bech B, Licht R, Kjaer D, Olsen J. Prenatal antidepressant exposure and behavioral problems in early childhood-a cohort study. Acta Psychiatr Scand. 2013;127(2):126-35.

31. Andrade C. Intellectual Disability After Gestational Exposure to Antidepressant Drugs: The Confidence Interval as a Compatibility Interval. J Clin Psychiatry. 2019;80(3):19f12912.

32. Skurtveit S, Selmer R, Roth C, Hernandez-Diaz S, Handal M. Prenatal exposure to antidepressants and language competence at age three: results from a large population-based pregnancy cohort in Norway. BJOG Int J Obstet Gynaecol. 2014;121(13):1621-31.

33. Malm H, Brown AS, Gissler M, Gyllenberg D, Hinkka-Yli-Salomäki S, McKeague IW, et al. Gestational exposure to selective serotonin reuptake inhibitors and offspring psychiatric disorders: a national register-based study. J Am Acad Child Adolesc Psychiatry. 2016;55(5):359-66.

34. Sujan AC, Rickert ME, Öberg AS, Quinn PD, Hernández-Díaz S, Almqvist C, et al. Associations of maternal antidepressant use during the first trimester of pregnancy with preterm birth, small for gestational age, autism spectrum disorder, and attention-deficit/hyperactivity disorder in offspring. JAMA. 2017;317(15):1553-62.

35. Brown HK, Ray JG, Wilton AS, Lunsky Y, Gomes T, Vigod SN. Association between serotonergic antidepressant use during pregnancy and autism spectrum disorder in children. JAMA. 2017;317(15):1544-52.

36. Payne JL, Meltzer-Brody S. Antidepressant use during pregnancy: current controversies and treatment strategies. Clin Obstet Gynecol. 2009;52(3):469.

37. Sockol LE, Epperson CN, Barber JP. A meta-analysis of treatments for perinatal depression. Clin Psychol Rev. 2011;31(5):839-49.

38. Stuart S, Koleva H. Psychological treatments for perinatal depression. Best Pract Res Clin Obstet Gynaecol. 2014;28(1):61-70.

39. Nillni Yl, Mehralizade A, Mayer L, Milanovic S. Treatment of depression, anxiety, and trauma-related disorders during the perinatal period: a systematic review. Clin Psychol Rev. 2018;66:136-48.

40. Goodman JH. Women's attitudes, preferences, and perceived barriers to treatment for perinatal depression. Birth. 2009;36(1):60-9.

41. Baskin R, Hill B, Jacka FN, O'Neil A, Skouteris $H$. The association between diet quality and mental health during the perinatal period. A systematic review. Appetite. 2015;91:41-7.

42. Sparling TM, Henschke N, Nesbitt RC, Gabrysch S. The role of diet and nutritional supplementation in perinatal depression: a systematic review. Matern Child Nutr. 2017;13(1):e12235.

43. Silva DFO, Cobucci RN, Gonçalves AK, Lima SCVC. Systematic review of the association between dietary patterns and perinatal anxiety and depression. BMC Pregnancy Childbirth. 2019;19(1):212.

44. Serati M, Redaelli M, Buoli M, Altamura A. Perinatal major depression biomarkers: a systematic review. J Affect Disord. 2016;193:391-404.
45. Lamb AR, Lutenbacher M, Wallston KA, Pepkowitz SH, Holmquist B, Hobel CJ. Vitamin D deficiency and depressive symptoms in the perinatal period. Arch Womens Ment Health. 2018;21(6):745-55.

46. Aghajafari F, Letourneau N, Mahinpey N, Cosic N, Giesbrecht G. Vitamin D deficiency and antenatal and postpartum depression: a systematic review. Nutrients. 2018;10(4):478.

47. Peppard L, Oh KM, Gallo S, Milligan R. Risk of depression in pregnant women with low-normal serum vitamin B12. Res Nurs Health. 2019;42(4): 264-72.

48. Sparling TM, Nesbitt RC, Henschke N, Gabrysch S. Nutrients and perinatal depression: a systematic review. J Nutr Sci. 2017;6:e61.

49. Wang J, Liu N, Sun W, Chen D, Zhao J, Zhang W. Association between vitamin $\mathrm{D}$ deficiency and antepartum and postpartum depression: a systematic review and meta-analysis of longitudinal studies. Arch Gynecol Obstet. 2018;298(6):1045-59.

50. Mertz W. A balanced approach to nutrition for health: the need for biologically essential minerals and vitamins. J Am Diet Assoc. 1994;94(11):1259-62.

51. Popper CW. Single-micronutrient and broad-spectrum micronutrient approaches for treating mood disorders in youth and adults. Child Adolesc Psychiatr Clin N Am. 2014;23(3):591-672.

52. Rucklidge JJ, Kaplan BJ. Broad-spectrum micronutrient formulas for the treatment of psychiatric symptoms: a systematic review. Expert Rev Neurother. 2013;13(1):49-73.

53. Su K-P, Huang S-Y, Chiu T-H, Huang K-C, Huang C-L, Chang H-C, et al. Omega-3 fatty acids for major depressive disorder during pregnancy: results from a randomized, double-blind, placebo-controlled trial. J Clin Psychiatry. 2008:69(4):644.

54. Nguyen PH, DiGirolamo AM, Gonzalez-Casanova I, Pham H, Hao W, Nguyen $\mathrm{H}$, et al. Impact of preconceptional micronutrient supplementation on maternal mental health during pregnancy and postpartum: results from a randomized controlled trial in Vietnam. BMC Womens Health. 2017;17(1):44.

55. Young JJ, Bruno D, Pomara N. A review of the relationship between proinflammatory cytokines and major depressive disorder. J Affect Disord. 2014;169:15-20.

56. Osborne LM, Monk C. Perinatal depression — the fourth inflammatory morbidity of pregnancy?: theory and literature review. Psychoneuroendocrinology. 2013;38(10):1929-52.

57. Warthon-Medina M, Qualter P, Zavaleta N, Dillon S, Lazarte F, Lowe NM. The long term impact of micronutrient supplementation during infancy on cognition and executive function performance in pre-school children. Nutrients. 2015;7(8):6606-27.

58. Nyaradi A, Li J, Hickling S, Foster J, Oddy WH. The role of nutrition in children's neurocognitive development, from pregnancy through childhood. Front Hum Neurosci. 2013;7:97.

59. Galera C, Heude B, Forhan A, Bernard JY, Peyre H, Van der Waerden J, et al. Prenatal diet and children's trajectories of hyperactivity-inattention and conduct problems from 3 to 8 years: the EDEN mother-child cohort. J Child Psychol Psychiatry. 2018;59(9):1003-11.

60. Miyake Y, Tanaka K, Okubo H, Sasaki S, Arakawa M. Maternal consumption of vegetables, fruit, and antioxidants during pregnancy and risk for childhood behavioral problems. Nutrition. 2020;69:110572.

61. Miyake Y, Tanaka K, Okubo H, Sasaki S, Arakawa M. Maternal B vitamin intake during pregnancy and childhood behavioral problems in Japan: the Kyushu Okinawa maternal and child health study. Nutr Neurosci. 2018;19:1-8.

62. Virk J, Liew Z, Olsen J, Nohr EA, Catov JM, Ritz B. Pre-conceptual and prenatal supplementary folic acid and multivitamin intake, behavioral problems, and hyperkinetic disorders: a study based on the Danish National Birth Cohort (DNBC). Nutr Neurosci. 2018;21(5):352-60.

63. Freedman R, Hunter SK, Hoffman MC. Prenatal Primary Prevention of Mental Illness by Micronutrient Supplements in Pregnancy. Am J Psychiatry. 2018. https://doi.org/10.1176/appi.ajp.2018.17070836.

64. Schmidt RJ, losif A-M, Angel EG, Ozonoff S. Association of maternal prenatal vitamin use with risk for autism spectrum disorder recurrence in young siblings. JAMA Psychiatry. 2019;76(4):391-8.

65. Kawai K, Spiegelman D, Shankar AH, Fawzi WW. Maternal multiple micronutrient supplementation and pregnancy outcomes in developing countries: meta-analysis and meta-regression. Bull World Health Organ. 2011;89(6):402-11.

66. Engle-Stone R, Kumordzie SM, Meinzen-Dick L, Vosti SA. Replacing iron-folic acid with multiple micronutrient supplements among pregnant women in 
Bangladesh and Burkina Faso: costs, impacts, and cost-effectiveness. Ann N Y Acad Sci. 2019;1444(1):35.

67. Cheng G, Sha T, Gao X, Wu X, Tian Q, Yang F, et al. Effects of maternal prenatal multi-micronutrient supplementation on growth and development until 3 years of age. Int J Environ Res Public Health. 2019;16(15):2744.

68. Vaidya A, Saville N, Shrestha BP. Anthony MdL, Manandhar DS, Osrin D. effects of antenatal multiple micronutrient supplementation on children's weight and size at 2 years of age in Nepal: follow-up of a double-blind randomised controlled trial. Lancet. 2008;371(9611):492-9.

69. Kaplan BJ, Rucklidge JJ, Romijn AR, Dolph M. A randomised trial of nutrient supplements to minimise psychological stress after a natural disaster. Psychiatry Res. 2015;228(3):373-9.

70. Lothian J, Blampied NM, Rucklidge JJ. Effect of micronutrients on insomnia in adults: a multiple-baseline study. Clin Psychol Sci. 2016;4(6):1112-24.

71. Rucklidge JJ, Andridge R, Gorman B, Blampied N, Gordon H, Boggis A. Shaken but unstirred? Effects of micronutrients on stress and trauma after an earthquake: RCT evidence comparing formulas and doses. Hum Psychopharmacol Clin Exp. 2012;27(5):440-54.

72. Rucklidge JJ, Blampied N, Gorman B, Gordon HA, Sole E. Psychological functioning 1 year after a brief intervention using micronutrients to treat stress and anxiety related to the 2011 Christchurch earthquakes: a naturalistic follow-up. Hum Psychopharmacol Clin Exp. 2014;29(3):230-43.

73. Rucklidge JJ, Frampton CM, Gorman B, Boggis A. Vitamin-mineral treatment of attention-deficit hyperactivity disorder in adults: double-blind randomised placebo-controlled trial. Br J Psychiatry. 2014;204(4):306-15.

74. Cox JL, Holden JM, Sagovsky R. Detection of postnatal depression. Development of the 10-item Edinburgh postnatal depression scale. $\mathrm{Br} J$ Psychiatry. 1987;150(6):782-6.

75. Boyd RC, Le H, Somberg R. Review of screening instruments for postpartum depression. Arch Womens Ment Health. 2005;8(3):141-53.

76. Bergink V, Kooistra L, Lambregtse-van den Berg MP, Wijnen H, Bunevicius R, van Baar A, et al. Validation of the Edinburgh depression scale during pregnancy. J Psychosom Res. 2011;70(4):385-9.

77. Gibson J, McKenzie-McHarg K, Shakespeare J, Price J, Gray R. A systematic review of studies validating the Edinburgh postnatal depression scale in antepartum and postpartum women. Acta Psychiatr Scand. 2009;119(5):350-64.

78. Murray D, Cox JL. Screening for depression during pregnancy with the Edinburgh depression scale (EDDS). J Reprod Infant Psychol. 1990;8(2):99-107.

79. Kozinszky Z, Dudas RB. Validation studies of the Edinburgh postnatal depression scale for the antenatal period. J Affect Disord. 2015;176:95-105.

80. Matthey S, Souter K, Mortimer K, Stephens C, Sheridan-Magro A. Routine antenatal maternal screening for current mental health: evaluation of a change in the use of the Edinburgh depression scale in clinical practice. Arch Womens Ment Health. 2016;19(2):367-72

81. Guy W. ECDEU assessment manual for psychopharmacology. Rockville: US Department of Health, Education and Welfare; 1976. p. 534-7.

82. Kadouri A, Corruble E, Falissard B. The improved clinical global impression scale (iCGI): development and validation in depression. BMC Psychiatry. 2007;7(1):7.

83. Berk M, Ng F, Dodd S, Callaly T, Campbell S, Bernardo M, et al. The validity of the CGI severity and improvement scales as measures of clinical effectiveness suitable for routine clinical use. J Eval Clin Pract. 2008;14(6):979-83.

84. Montgomery SA, Åsberg M. A new depression scale designed to be sensitive to change. Br J Psychiatry. 1979;134(4):382-9.

85. Williams JB, Kobak KA. Development and reliability of a structured interview guide for the Montgomery-Åsberg depression rating scale (SIGMA). Br J Psychiatry. 2008;192(1):52-8.

86. Lovibond PF, Lovibond SH. The structure of negative emotional states: comparison of the depression anxiety stress scales (DASS) with the Beck depression and anxiety inventories. Behav Res Ther. 1995;33(3): 335-43.

87. Henry JD, Crawford JR. The short-form version of the depression anxiety stress scales (DASS-21): construct validity and normative data in a large nonclinical sample. Br J Clin Psychol. 2005;44(2):227-39.

88. Spitzer RL, Kroenke K, Williams JB, Löwe B. A brief measure for assessing generalized anxiety disorder: the GAD-7. Arch Intern Med. 2006;166(10):1092-7.

89. Löwe B, Decker O, Müller S, Brähler E, Schellberg D, Herzog W, et al. Validation and standardization of the generalized anxiety disorder screener (GAD-7) in the general population. Med Care. 2008;46(3):266-74.

90. Simpson W, Glazer M, Michalski N, Steiner M, Frey BN. Comparative efficacy of the generalized anxiety disorder 7-item scale and the Edinburgh postnatal depression scale as screening tools for generalized anxiety disorder in pregnancy and the postpartum period. Can J Psychiatry. 2014; 59(8):434-40.

91. Cohen S, Kamarck T, Mermelstein R. A global measure of perceived stress. J Health Soc Behav. 1983;24:385-96.

92. Lee $\mathrm{E}-\mathrm{H}$. Review of the psychometric evidence of the perceived stress scale. Asian Nurs Res. 2012:6(4):121-7.

93. Ware JE Jr, Kosinski M, Keller SD. A 12-item short-form health survey: construction of scales and preliminary tests of reliability and validity. Med Care. 1996;34(3):220-33.

94. Salyers MP, Bosworth HB, Swanson JW, Lamb-Pagone J, Osher FC. Reliability and validity of the SF-12 health survey among people with severe mental illness. Med Care. 2000;38(11):1141-50.

95. Bai G, Korfage IJ, Hafkamp-de Groen E, Jaddoe WW, Mautner E, Raat H. Associations between nausea, vomiting, fatigue and health-related quality of life of women in early pregnancy: the generation R study. PLoS One. 2016;11(11):e0166133.

96. Hammarberg K, Wynter K, Fisher J, McBain J, Gibson F, Boivin J, et al. The experience of pregnancy: does age or mode of conception matter? J Reprod Infant Psychol. 2013;31(2):109-20.

97. Kaufman EA, Xia M, Fosco G, Yaptangco M, Skidmore CR, Crowell SE. The difficulties in emotion regulation scale short form (DERS-SF): validation and replication in adolescent and adult samples. J Psychopathol Behav Assess. 2016;38(3):443-55.

98. Hallion LS, Steinman SA, Tolin DF, Diefenbach GJ. Psychometric properties of the difficulties in emotion regulation scale (DERS) and its short forms in adults with emotional disorders. Front Psychol. 2018;9:539.

99. Association AP. DSM-IV-TR: diagnostic and statistical manual of mental disorders, text revision, vol. 75. Washington, DC: American Psychiatric Association; 2000. p. 78-85.

100. Hilsenroth MJ, Ackerman SJ, Blagys MD, Baumann BD, Baity MR, Smith SR, et al. Reliability and validity of DSM-IV axis V. Am J Psychiatr. 2000;157(11): 1858-63.

101. Uher R, Farmer A, Henigsberg N, Rietschel M, Mors O, Maier W, et al. Adverse reactions to antidepressants. Br J Psychiatry. 2009;195(3):202-10.

102. Buysse DJ, Reynolds CF, Monk TH, Berman SR, Kupfer DJ. The Pittsburgh sleep quality index: a new instrument for psychiatric practice and research. Psychiatry Res. 1989;28(2):193-213.

103. Jomeen J, Martin CR. Assessment and relationship of sleep quality to depression in early pregnancy. J Reprod Infant Psychol. 2007;25(1):87-99.

104. Rallis S, Skouteris H, McCabe M, Milgrom J. A prospective examination of depression, anxiety and stress throughout pregnancy. Women Birth. 2014; 27(4):e36-42.

105. Skouteris H, Germano C, Wertheim EH, Paxton SJ, Milgrom J. Sleep quality and depression during pregnancy: a prospective study. J Sleep Res. 2008; 17(2):217-20.

106. Bharmal M, Payne K, Atkinson MJ, Desrosiers M-P, Morisky DE, Gemmen E. Validation of an abbreviated treatment satisfaction questionnaire for medication (TSQM-9) among patients on antihypertensive medications. Health Qual Life Outcomes. 2009;7(1):36.

107. Zimet GD, Dahlem NW, Zimet SG, Farley GK. The multidimensional scale of perceived social support. J Pers Assess. 1988;52(1):30-41.

108. Skouteris H, Wertheim EH, Rallis S, Milgrom J, Paxton SJ. Depression and anxiety through pregnancy and the early postpartum: an examination of prospective relationships. J Affect Disord. 2009;113(3):303-8.

109. Bergman K, Sarkar P, O'connor TG, Modi N, Glover V. Maternal stress during pregnancy predicts cognitive ability and fearfulness in infancy. J Am Acad Child Adolesc Psychiatry. 2007:46(11):1454-63.

110. Heatherton TF, Kozlowski LT, Frecker RC, Rickert W, Robinson J. Measuring the heaviness of smoking: using self-reported time to the first cigarette of the day and number of cigarettes smoked per day. Addiction. 1989;84(7): 791-800.

111. Borland R, Yong H-H, O'connor R, Hyland A, Thompson M. The reliability and predictive validity of the Heaviness of Smoking Index and its two components: findings from the International Tobacco Control Four Country study. Nicotine Tob Res. 2010;12(suppl_1):S45-50.

112. Bush K, Kivlahan DR, McDonell MB, Fihn SD, Bradley KA. The AUDIT alcohol consumption questions (AUDIT-C): an effective brief screening test for problem drinking. Arch Intern Med. 1998;158(16):1789-95.

113. Burns E, Gray R, Smith LA. Brief screening questionnaires to identify problem drinking during pregnancy: a systematic review. Addiction. 2010;105(4):601-14. 114. Skinner HA. The drug abuse screening test. Addict Behav. 1982;7(4):363-71. 
115. Bailey RL, Miller PE, Mitchell DC, Hartman TJ, Lawrence FR, Sempos CT, et al. Dietary screening tool identifies nutritional risk in older adults. Am J Clin Nutr. 2009;90(1):177-83.

116. Cavicchia PP, Steck SE, Hurley TG, Hussey JR, Ma Y, Ockene IS, et al. A new dietary inflammatory index predicts interval changes in serum highsensitivity C-reactive protein. J Nutr. 2009;139(12):2365-72.

117. Peeters FP, Ruhe HG, Wichers M, Abidi L, Kaub K, van der Lande HJ, et al. The Dutch measure for quantification of treatment resistance in depression (DM-TRD): an extension of the Maudsley staging method. J Affect Disord. 2016;205:365-71.

118. Fekadu A, Wooderson S, Donaldson C, Markopoulou K, Masterson B, Poon L, et al. A multidimensional tool to quantify treatment resistance in depression: the Maudsley staging method. J Clin Psychiatry. 2009;70(2):177-84.

119. Moran $P$, Leese $M$, Lee $T$, Walters $P$, Thornicroft G, Mann A. Standardised assessment of personality-abbreviated scale (SAPAS): preliminary validation of a brief screen for personality disorder. Br J Psychiatry. 2003;183(3):228-32.

120. Als H, Tronick E, Lester BM, Brazelton TB. The Brazelton neonatal behavioral assessment scale (BNBAS). J Abnorm Child Psychol. 1977;5(3):215-29.

121. Tosun O, Erdem E, Elmali F, Kurtoglu S. Brazelton neonatal behavioral assessment scale; a validity and reliability study in a Turkey sample. Pediatr Crit Care Med. 2014;15(4):96.

122. Tronick E, Als H, Adamson L, Wise S, Brazelton TB. The infant's response to entrapment between contradictory messages in face-to-face interaction. J Am Acad Child Psychiatry. 1978;17(1):1-13.

123. Cohn JF, Tronick EZ. Three-month-old infants' reaction to simulated maternal depression. Child Dev. 1983;54(1):185-93.

124. Adamson LB, Frick JE. The still face: a history of a shared experimental paradigm. Infancy. 2003;4(4):451-73.

125. Braungart-Rieker J, Garwood MM, Powers BP, Notaro PC. Infant affect and affect regulation during the still-face paradigm with mothers and fathers: the role of infant characteristics and parental sensitivity. Dev Psychol. 1998; 34(6):1428.

126. Mesman J, van IJzendoorn MH, Bakermans-Kranenburg MJ. The many faces of the still-face paradigm: a review and meta-analysis. Dev Rev. 2009;29(2): 120-62.

127. Brockington IF, Oates J, George S, Turner D, Vostanis P, Sullivan M, et al. A screening questionnaire for mother-infant bonding disorders. Arch Womens Ment Health. 2001;3(4):133-40.

128. Wittkowski A, Wieck A, Mann S. An evaluation of two bonding questionnaires: a comparison of the mother-to-infant bonding scale with the postpartum bonding questionnaire in a sample of primiparous mothers. Arch Womens Ment Health. 2007;10(4):171-5.

129. Rothbart MK. Measurement of temperament in infancy. Child Dev. 1981;52: 569-78.

130. James-Roberts I, Halil T. Infant crying patterns in the first year: normal community and clinical findings. J Child Psychol Psychiatry. 1991;32(6):951-68.

131. Alvarez M, St James-Roberts I. Infant fussing and crying patterns in the first year in an urban community in Denmark. Acta Paediatr. 1996;85(4):463-6.

132. James-Roberts I, Bowyer J, Varghese S, Sawdon J. Infant crying patterns in Manali and London. Child Care Health Dev. 1994;20(5):323-37.

133. Wolke D, Meyer R, Gray P. Validity of the crying pattern questionnaire in a sample of excessively crying babies. J Reprod Infant Psychol. 1994;12(2):105-14.

134. Squires J, Bricker D, Potter L. Revision of a parent-completed developmenta screening tool: ages and stages questionnaires. J Pediatr Psychol. 1997;22(3): 313-28.

135. Henderson JM, France KG, Owens JL, Blampied NM. Sleeping through the night: the consolidation of self-regulated sleep across the first year of life. Pediatrics. 2010;126(5):e1081-7.

136. Zealand SN. Births and deaths: year ended December 2014. Wellington: Statistics New Zealand; 2015.

137. Paoletti AM, Orru MM, Marotto MF, Pilloni M, Zedda P, Fais MF, et al. Observational study on the efficacy of the supplementation with a preparation with several minerals and vitamins in improving mood and behaviour of healthy puerperal women. Gynecol Endocrinol. 2013;29(8):779-83.

138. Mech AW, Farah A. Correlation of clinical response with homocysteine reduction during therapy with reduced $B$ vitamins in patients with MDD who are positive for MTHFR C677T or A1298C polymorphism: a randomized, double-blind, placebo-controlled study. J Clin Psychiatry. 2016;77(5):668-71.

139. First M, Williams J, Karg R, Spitzer R. Structured clinical interview for DSM-5 disorders, clinician version (SCID-5-CV). Arlington: American Psychiatric Association; 2015.
140. StataCorp. In: LLC S, editor. Stata Statistical Software: Release 15. College Station, TX: StataCorp LP; 2017

141. Matthey S. Calculating clinically significant change in postnatal depression studies using the Edinburgh postnatal depression scale. J Affect Disord. 2004;78(3):269-72

142. Legislation NZ. Accident Compensation Act 2001. Retrieved from http:// www.legislation.govt.nz/act/public/2001/0049/latest/DLM99494.html.

143. Health Mo. Standard operating procedures for health and disability ethics committees. New Zealand: Ministry of Health; 2014.

\section{Publisher's Note}

Springer Nature remains neutral with regard to jurisdictional claims in published maps and institutional affiliations.
Ready to submit your research? Choose BMC and benefit from:

- fast, convenient online submission

- thorough peer review by experienced researchers in your field

- rapid publication on acceptance

- support for research data, including large and complex data types

- gold Open Access which fosters wider collaboration and increased citations

- maximum visibility for your research: over $100 \mathrm{M}$ website views per year

At BMC, research is always in progress.

Learn more biomedcentral.com/submissions 